Translation of a C. difficile Treatment Clinical Pathway Into Machine-Readable Clinical Decision Support Artifacts Prototyped for Electronic Health Record Integration 


\title{
Translation of a $C$. difficile Treatment Clinical Pathway Into Machine-Readable Clinical Decision Support Artifacts Prototyped for Electronic Health Record Integration
}

\author{
Prepared for: \\ Agency for Healthcare Research and Quality \\ U.S. Department of Health and Human Services \\ 5600 Fishers Lane \\ Rockville, MD 20857 \\ www.ahrq.gov
}

Contract No. 290-2015-00005-I

Prepared by:

ECRI Institute-Penn Medicine Evidence-based Practice Center

Plymouth Meeting, PA

Investigators:

Jeremy Michel, M.D., M.H.S.*

Emilia Flores, Ph.D., R.N.*

Nikhil Mull, M.D.

Amy Y. Tsou, M.D., M.Sc.

*Dr. Michel and Dr. Flores contributed equally to this report

AHRQ Publication No. 20-EHC001-EF

November 2019 


\section{Key Messages}

\section{Purpose of Project}

To translate an evidence-based Clostridioides difficile* (CDI) treatment clinical pathway using a systematic, transparent process into machine readable clinical decision support (CDS) prototyped for electronic health record (EHR) integration. (*The bacterium Clostridium difficile was renamed Clostridioides difficile in August 2016.)

\section{Key Messages}

- Getting evidence into practice to improve clinical decision making remains an ongoing challenge.

- We successfully translated a clinical pathway into machine readable CDS prototyped for EHR integration.

- We used the CDS Authoring Tool on the CDS Connect website to translate this clinical pathway into Clinical Quality Language (CQL) shareable decision support.

- Creating CDS artifacts from a clinical pathway informed by an EPC report may promote dissemination of work from AHRQ reports to a wide audience and support AHRQ's Learning Health System initiatives. 
This report is based on research conducted by the ECRI Institute - Penn Medicine Evidencebased Practice Center (EPC) under contract to the Agency for Healthcare Research and Quality (AHRQ), Rockville, MD (Contract No. 290-2015-00005-I). The findings and conclusions in this document are those of the authors, who are responsible for its contents; the findings and conclusions do not necessarily represent the views of AHRQ. Therefore, no statement in this report should be construed as an official position of AHRQ or of the U.S. Department of Health and Human Service

\section{None of the investigators have any affiliations or financial involvement that conflicts with the material presented in this report.}

The information in this report is intended to help healthcare decision makers—patients and clinicians, health system leaders, and policymakers, among others-make well-informed decisions and thereby improve the quality of healthcare services. This report is not intended to be a substitute for the application of clinical judgment. Anyone who makes decisions concerning the provision of clinical care should consider this report in the same way as any medical reference and in conjunction with all other pertinent information, i.e., in the context of available resources and circumstances presented by individual patients.

This report is made available to the public under the terms of a licensing agreement between the author and the Agency for Healthcare Research and Quality. This report may be used and reprinted without permission except those copyrighted materials that are clearly noted in the report. Further reproduction of those copyrighted materials is prohibited without the express permission of copyright holders.

AHRQ or U.S. Department of Health and Human Services endorsement of any derivative products that may be developed from this report, such as clinical practice guidelines, other quality enhancement tools, or reimbursement or coverage policies, may not be stated or implied.

Persons using assistive technology may not be able to fully access information in this report. For assistance contact EPC@ahrq.hhs.gov.

Suggested citation: Michel J, Flores E, Mull N, Tsou AY. Translation of a Clinical Pathway for C. Difficile Treatment Into a Machine-Readable Clinical Decision Support Artifact Prototyped for Electronic Health Record Integration. Methods Research Report. (Prepared by the ECRI Institute -Penn Medicine Evidence-based Practice Center under Contract No. 290-2015-00005I.) AHRQ Publication No. 20-EHC001-EF. Rockville, MD: Agency for Healthcare Research and Quality; November 2019. Posted final reports are located on the Effective Health Care Program search page. DOI: https://doi.org/10.23970/AHRQEPCMETHQUALIMPRCDIFF. 


\section{Preface}

The Agency for Healthcare Research and Quality (AHRQ), through its Evidence-based Practice Centers (EPCs), sponsors the development of evidence reports and technology assessments to assist public- and private-sector organizations in their efforts to improve the quality of healthcare in the United States. The reports and assessments provide organizations with comprehensive, science-based information on common, costly medical conditions and new healthcare technologies and strategies. The EPCs systematically review the relevant scientific literature on topics assigned to them by AHRQ and conduct additional analyses when appropriate prior to developing their reports and assessments.

To improve the scientific rigor of these evidence reports, AHRQ supports empiric research by the EPCs to help understand or improve complex methodologic issues in systematic reviews. These methods research projects are intended to contribute to the research base in and be used to improve the science of systematic reviews. They are not intended to be guidance to the EPC program, although may be considered by EPCs along with other scientific research when determining EPC program methods guidance.

AHRQ expects that the EPC evidence reports and technology assessments will inform individual health plans, providers, and purchasers as well as the healthcare system as a whole by providing important information to help improve healthcare quality. The reports undergo peer review prior to their release as a final report.

If you have comments on this Methods Research Project they may be sent by mail to the Task Order Officer named below at: Agency for Healthcare Research and Quality, 5600 Fishers Lane, Rockville, MD 20857, or by email to epc@ahrq.hhs.gov.

Gopal Khanna, M.B.A.

Director

Agency for Healthcare Research and Quality

Stephanie Chang, M.D., M.P.H.

Director

Evidence-based Practice Center Program

Center for Evidence and Practice Improvement Agency for Healthcare Research and Quality
Arlene Bierman, M.D., M.S.

Director

Center for Evidence and Practice Improvement Agency for Healthcare Research and Quality

Kim Marie Wittenberg, M.A.

Task Order Officer

Center for Evidence and Practice Improvement Agency for Healthcare Research and Quality 


\section{Acknowledgments}

The authors gratefully acknowledge the following individuals for their contributions to this project: ECRI Institute: Jane Jue, M.D., M.Sc., Amber Moran, M.A., Kariann Hudson, M.Ed., Jennifer Maslin, and Nicholas Lepkowski; Penn Medicine: Lauren Dutcher, M.D., and AHRQ: Kim Wittenberg, M.A. 


\section{Translation of a C. difficile Treatment Clinical Pathway Into Machine-Readable Clinical Decision Support Artifacts Prototyped for Electronic Health Record Integration}

\section{Structured Abstract}

Background. Translating evidence into tools that improve clinical decision making remains an ongoing challenge. In 2018, the ECRI Institute - Penn Medicine Evidence Based Practice Center (EPC) utilized the 2016 AHRQ EPC report update on the Early Diagnosis, Prevention, and Treatment of Clostridium difficile* to develop a clinical pathway for the treatment of Clostridium difficile infection (CDI) in the acute care setting. In this AHRQ EPC methods project, we sought to develop a rigorous process to further translate the previously created CDI treatment clinical pathway into clinical decision support tools prototyped for integration into the Penn Medicine electronic health record (EHR). (*Note that the bacterium Clostridium difficile was renamed Clostridioides difficile in August 2016.)

Methods. A core team including the pathway program manager at the University of Pennsylvania Health System (UPHS), and physicians with subject matter, evidence synthesis, and informatics expertise was assembled. We developed a step-wise, task based, iterative process to ensure feasibility of evidence translation from the original CDI treatment clinical pathway to our final products. Publicly available tools such as electronic GuideLine Implementation Assessment (eGLIA), Guideline Elements Model (GEM), and the Value Set Authority Center (VSAC) were utilized to perform a systematic, transparent, and reproducible translation process.

Results. We successfully translated a clinical pathway into machine-readable clinical decision support (CDS) prototyped for EHR integration. Using the CDS Authoring Tool on CDS Connect, we translated this clinical guidance into encoded Clinical Quality Language (CQL) and to support the creation and dissemination of shareable decision support. Findings from this translation effort led to improvements in the source CDI treatment pathway. Following an agile systems development life-cycle process reduced ambiguity and improved clarity for both the source CDI pathway and CDS products.

Discussion. Several lessons learned emerged from this project. Early and ongoing collaboration between clinical subject experts and the CDS development team accelerated development and adaptation of evidence into machine readable CDS. Future enhancements to the CDS Authoring Tool will enhance its utility and productivity. Our process utilized publicly accessible tools to develop transparent and reproducible CDS products. Moving forward, instruments to assess the quality of clinical pathways and CDS will be necessary to encourage organizations to utilize shareable CDS, a long term goal for repositories such as CDS Connect. 


\section{Contents}

Introduction ............................................................................................................................. 1

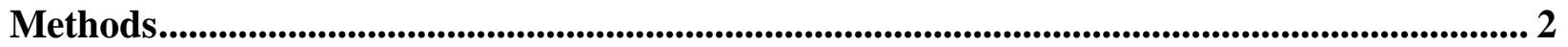

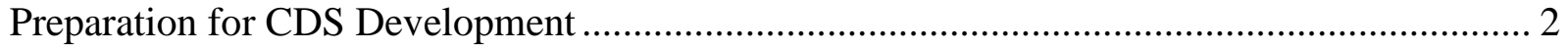

L3 Clinical Decision Support Development Framework............................................................. 2

Task 1. Extract L2 Recommendation Statements, Classify, and Assess for CDS Inclusion

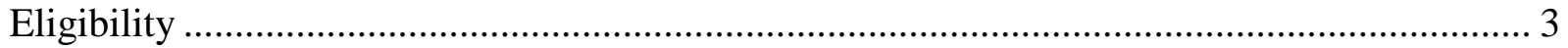

Task 2. Assess Feasibility and Barriers for Conversion of L2 to L3 CDS Artifact..................... 4

Task 3. Group Recommendation Statements by Clinical Phase and Target CDS Channel ....... 4

Task 4. Select CDS Intervention Type and Develop Interface Wireframe Prototypes ............... 4

Task 5. Parse Recommendations and Restructure Content for Encoding ................................... 4

Task 6. Meta-Tagging and Creation of Standardized Value Sets ................................................. 5

Task 7. Encode Recommendations Using CQL ………............................................................ 5

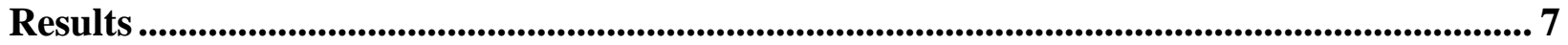

Task 1. Extract Data, Catalog, and Assess for CDS Inclusion Eligibility ................................... 7

Task 2. Assess Feasibility and Identify Barriers for Conversion to L3 CDS Artifact................. 8

Task 3. Categorize Recommendation Statements by Clinical Phase............................................ 9

Task 4. Identify Appropriate CDS Intervention Types To Support Implementation of the CDS Artifact and Develop Interface Wireframe Prototypes …………………………………............. 9

Task 5. Prepare Content for Encoding ............................................................................... 11

Task 6. Meta-Tagging and Creation of Standardized Value Sets ............................................. 11

Task 7. Encode Recommendations Using CQL ................................................................... 12

Summary of Final Work Products .................................................................................. 13

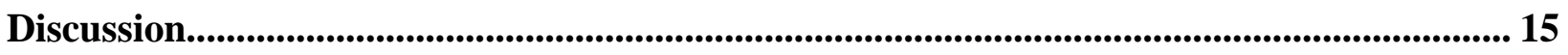

Lessons Learned............................................................................................................... 15

Lesson 1: Publicly Available Software for Translating Guideline Recommendations Into

CDS Can Be Used To Create and Maintain Trustworthy CDS Artifacts From Clinical

Pathways

Lesson 2: Early and Continuous Collaboration Between Subject Matter Experts and Clinical Informaticists Improved Clinical Accuracy and Usability of the Final CDS End Products. 15 Lesson 3: Utilizing an Iterative Development Process Improved the Quality of the Source CDI Treatment Pathway and Interim CDS Products ............................................................ 16

Lesson 4: Developing an L3 CDS Artifact From a Trustworthy Evidence-Based Clinical Pathway Offered Efficiency Gains .................................................................................. 17

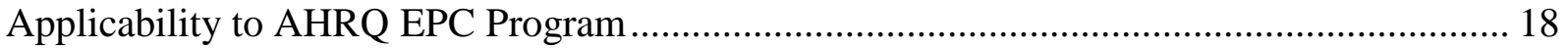

Creating CDS From EPC Report-Informed Clinical Pathways Can Promote Widespread Dissemination of Evidence Into Clinical Practice and Support AHRQ's Learning Health System Initiatives 
EPC Reports Should Include Summaries of Existing Guidelines To Improve Efficiencies for Clinical Pathway Development....................................................................................... 18

Developing a CDI Treatment Quality Measure May Demonstrate Use of AHRQ EPC

Reports To Support Quality Improvement Programs for Health Systems............................. 18

Improved Standards for Interoperability and Public Investment in the Development of

Shareable CDS Artifacts Create Opportunities for Widespread CDS Use and Adaptation . 19

Future Research and Projects.

Enhancements to CDS Connect and the CDS Authoring Tool Can Improve Clinical Accuracy and Expand Adaption of CDS Artifacts by a Wider Audience ... 19

Development of Tools and an Environment for Conducting End User L3 and L4 Artifact

Testing To Assess Fidelity To Source Evidence-Based Recommendations Is Needed ....... 20 Validated Instruments for Trustworthiness of Decision Support (and Evidence Sources) Are Needed To Promote Selection and Evaluation of Shareable CDS ........................................ 20

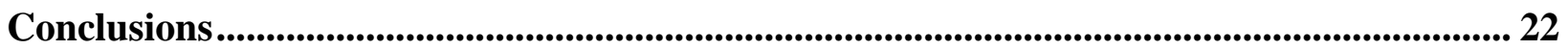

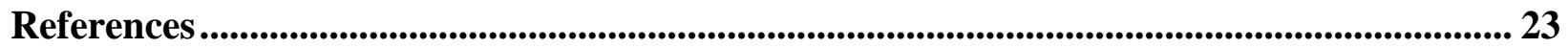

Tables

Table 1. Layers of CDS knowledge abstraction and translation..................................................... 1

Table 2. CDS Design and Development Tasks........................................................................ 3

Table 3. Recommendation statements extracted from the CDI pathway...................................... 7

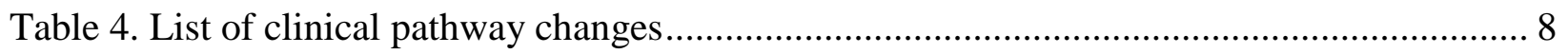

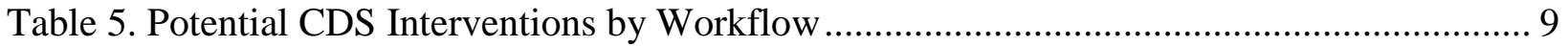

Table 6. CQL CDS Authoring Tool forms and descriptions ........................................................... 12

Table 7. Summary of issues encountered during CQL encoding using the CDS Authoring Tool

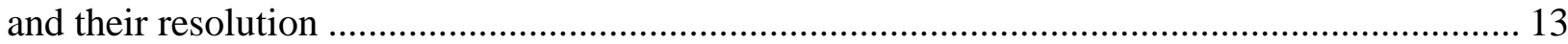

\section{Figures}

Figure 1. Clinical Decision Support Lifecycle ………............................................................ 2

Figure 2. Partial view of CDI Treatment Clinical Pathway........................................................... 3

Figure 3. CDS Connect CQL Authoring Tool Data Entry Interface ................................................ 6

\section{Appendixes}

Appendix A. eGLIA Report (Limited to Fields With Comments)

Appendix B. Original CDI Pathway

Appendix C. Updated CDI Pathway

Appendix D. Wireframe Mockup of Penn CDS Artifact

Appendix E. Guideline Elements Model (GEM) Report

Appendix F. Value Set Expansion of Clostridium difficile Infection 


\section{Introduction}

Translating scientific evidence into clinical practice remains an ongoing challenge. ${ }^{1-4}$ Clinical decision support (CDS) tools within the electronic health record (EHR) are one method that can be used to bridge the evidence-practice gap. ${ }^{5-8}$ However, CDS tools are expensive to develop and maintain,,${ }^{9,} 10$ presenting a significant barrier for adoption by most health settings. ${ }^{11}$ Recent advances in standards for data exchange and interoperability ${ }^{12}$ and public investment in infrastructure to support the development of shareable CDS artifacts ${ }^{13}$ may promote widespread implementation of these tools. ${ }^{11,14}$

CDS artifacts can be described according the degree in which they are interoperable across health settings and electronic health record systems. Boxwala et al. developed a four-tiered schema to describe these layers (L1-L4) of CDS knowledge abstraction and translation (Table 1). ${ }^{15}$

Significant hurdles exist to translate CDS artifacts from human readable form (L1-2) to a computer readable and executable structure (L3-4). In 2018, the ECRI Institute - Penn Medicine AHRQ EPC used the 2016 AHRQ EPC report update on the Early Diagnosis, Prevention, and Treatment of Clostridium difficile* to inform the development of a clinical pathway for Clostridium difficile infection (CDI) treatment in the acute care setting. (*Note that the bacterium Clostridium difficile was renamed Clostridioides difficile in August 2016.) This pathway was deployed within the University of Pennsylvania Health System (UPHS) as a resource that clinicians could access by clicking a link from within the electronic medical record (EMR). In this project, our goal was to convert this clinical pathway into a format that would facilitate full integration into the Penn Medicine electronic health record (EHR).

To that end, this AHRQ EPC methods project had two primary aims:

1. To use a systematic process to translate an evidence-based clinical pathway (L2) for Clostridium difficile infection (CDI) treatment into structured (L3) and executable (L4) artifacts and present lessons learned and implications for future work from this process.

2. To identify an optimal CDS channel (e.g. alert, order set) to implement recommendations and design an interface using the University of Pennsylvania Health System (UPHS) context as an exemplar.

Between publication of that clinical pathway and this report, the bacterium was renamed from Clostridium difficile to Clostridioides difficile; we will use the name C.difficile for the remainder of the report.

Table 1. Layers of CDS knowledge abstraction and translation

\begin{tabular}{|c|c|}
\hline CDS Level & Description \\
\hline L1 CDS (Narrative) & $\begin{array}{l}\text { Clinical decision support is presented as unstructured narrative statements, such as } \\
\text { clinical practice guideline recommendation statements. This level of CDS is not directly } \\
\text { interpretable by computers. }\end{array}$ \\
\hline $\begin{array}{l}\text { L2 CDS } \\
\text { (Semi-structured) }\end{array}$ & $\begin{array}{l}\text { Narrative text is organized into logical flows, as in a pathway or workflow document. } \\
\text { Clinicians can use information in this format to guide care; however, a computer is not } \\
\text { directly able to read information in this format to provide electronic decision support. }\end{array}$ \\
\hline L3 CDS (Structured) & $\begin{array}{l}\text { Information has been translated into a computer-readable format. Information has been } \\
\text { fully specified and encoded using standard terminologies, such as LOINC. Logic is } \\
\text { expressed using the clinical quality language (CQL) or another computable format. }{ }^{16} \\
\text { This format is still human readable, but is standardized such that clinical quality } \\
\text { concepts and knowledge can be exchanged across entities. }\end{array}$ \\
\hline L4 CDS (Executable) & $\begin{array}{l}\text { Artifacts in this format can be actively used within an EHR. In addition to being fully } \\
\text { expressed using a computer-readable format, the information needed to effectively } \\
\text { utilize the CDS (e.g. how to access a problem list within a patient object, or add an } \\
\text { order to an order list) is also embedded within the artifact or the EHR. }\end{array}$ \\
\hline
\end{tabular}




\section{Methods}

\section{Preparation for CDS Development}

We assembled a five member team with expertise across clinical and technical domains, including a fellowship-trained physician clinical informaticist (with technical expertise in L3 artifact development), a clinical guideline methodologist (evidence synthesis and recommendation writing expertise), the UPHS clinical pathways program manager (evidence translation, design and implementation expertise), a practicing, fellowship-trained infectious disease physician (subject matter expertise), and a practicing hospitalist (subject matter, evidence synthesis, design and implementation expertise).

To ensure CDS artifacts were being developed from the most recent evidence base, we conducted a targeted literature search (January 20, 2017 through January 11, 2019) from the completion of the previous AHRQ EPC report update to identify any changes in evidence or recommendations that might impact development of the CDS artifact. We identified 29 citations, which were reviewed for relevance by a clinician analyst. No studies were identified that directly impacted clinical care outlined within the clinical pathway.

\section{L3 Clinical Decision Support Development Framework}

Development of the shareable L3 CDS artifact was organized into two main phases: (1) analysis and preparation and (2) development (Figure 1). During analysis and preparation, guidance from the clinical pathway is extracted into recommendation statements. This phase also includes identifying impacted clinical workflow phases (e.g. diagnosis, therapy initiation, monitoring, etc.) and assessment of which recommendations would be suitable candidates for further development into the L3 CDS artifact. During the development phase, knowledge in the form of human-readable text (e.g. guidelines and pathways) is systematically translated into structured data and converted into standardized content. The development phase uses standardized terminologies and CQL authoring tools to create machine-readable data. Details for each phase and associated tasks are presented in Table 2.

For this project, we also included a phase for developing an artifact interface prototype (Figure 1, design phase). This phase was included to operationalize the content and develop a prototype interface for the local context (i.e. UPHS) in preparation for potential L4 CDS artifact completion.

Figure 1. Clinical decision support lifecycle

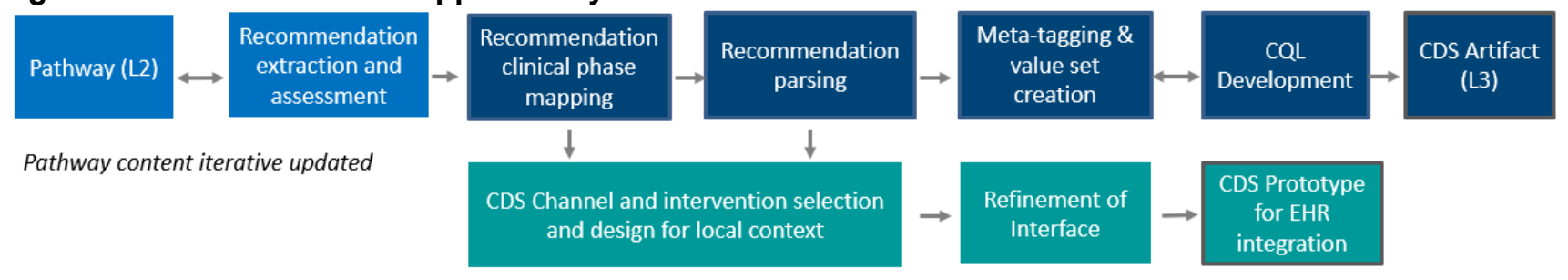


Table 2. CDS design and development tasks

\begin{tabular}{|l|l|l|}
\hline \multicolumn{1}{|c|}{ Phase } & Tasks & \multicolumn{1}{c|}{ Description } \\
\hline Analysis & T1 & $\begin{array}{l}\text { Extract L2 recommendation statements from clinical pathway, classify, and assess for } \\
\text { L3 CDS artifact inclusion eligibility }\end{array}$ \\
\hline Analysis & T2 & Assess feasibility and barriers for conversion to L3 CDS artifact \\
\hline Analysis & T3 & Assign clinical phase and target interventions to each statement \\
\hline Design & T4 & Select a CDS channel and develop wireframe prototypes for L4 CDS planning \\
\hline Development & T5 & Parse recommendations and restructure content for encoding \\
\hline Development & T6 & Meta-tagging and creation of standardized value sets \\
\hline Development & T7 & Encode recommendations using CQL \\
\hline
\end{tabular}

\section{Task 1. Extract L2 Recommendation Statements, Classify, and Assess for CDS Inclusion Eligibility}

Clinical guidance offered in the CDI treatment pathway is organized into a clinical algorithm with information embedded within steps and clinical decision nodes. The purpose of this task is to extract recommendations from the pathway into discrete actionable statements, classify by intervention type (e.g. order vs. diagnose), and assess for inclusion for the L3 CDS build.

For this task, pathway statements should first be extracted and tabulated. Unique identifiers should be generated for each statement consisting of clinical category, numerical identifier, and a short summary statement. Potential clinical categories include order (O), refer (R), consider (C), diagnose (D), monitor (M), or laboratory testing (L). For example, the CDI recurrence node (Figure 2) contained the following statement: "Diagnose a recurrent CDI if positive C. difficile test and recurrent symptoms attributable to CDI within 8 weeks of successfully completing treatment for previous CDI that was associated with interval improvement.” This statement was tabulated, categorized as "diagnosis (D)," enumerated as " 3 " since it was the third statement related to diagnosis, and summarized as "Diagnose Recurrent CDI." The final identifier was expressed as “D3: Diagnose Recurrent CDI.” Ideally, extracted statements, classification, and enumeration should be reviewed by separate team members for accuracy.

In this phase, an initial review should be performed to assess if any recommendations would clearly not be candidates for further development into L3 CDS. Reasons for excluding recommendations could include feasibility considerations (e.g. data needed for the recommendation that is not available within EHR) or if a recommendation pertained to something outside of the pathway's clinical scope (e.g. diagnosis of CDI, which is addressed in a separate pathway).

Figure 2. Partial view of CDI treatment clinical pathway

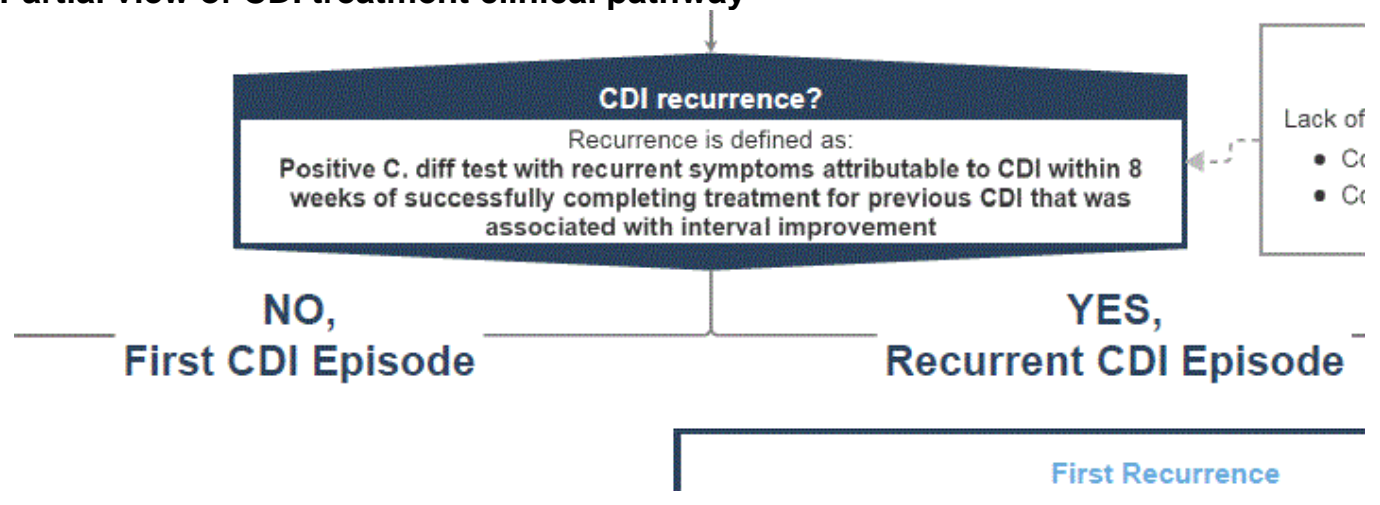




\section{Task 2. Assess Feasibility and Barriers for Conversion of L2 to L3 CDS Artifact}

The purpose of this task is to identify potential barriers and feasibility challenges of L2 to L3 CDS artifact conversion. The GuideLine Implementability Appraisal (eGLIA) tool, a publicly accessible web-based tool, allows identification of potential barriers to CDS conversion for guideline recommendations. ${ }^{17}$ Each recommendation statement is assessed across key domains necessary for CDS conversion including executability, decidability, validity, flexibility, effect on process of care, measurability, novelty/innovation, and computability. For each domain, the tool asks if a recommendation statement has a potential barrier (Yes/No/Unsure) and if so, respondents are asked to describe concerns in a comments field. After all team members complete the eGLIA assessment, discordant response and barriers to implementation should be discussed.

\section{Task 3. Group Recommendation Statements by Clinical Phase and Target CDS Channel}

Identifying the right time within clinical workflow and the right channel (e.g. EHR, mobile application, patient portal, other media format) for the CDS intervention is fundamental to the success of electronic decision support interventions. ${ }^{14}$ The purpose of this task is to categorize extracted statements by workflow phase. This information is critical to inform selection of the optimal CDS channel and intervention, and interface design (in Task 4).

The stakeholder team should review each extracted statement and assess the most clinical workflow phase (e.g. treatment selection, initiation, monitoring, completion, and followup) during which the decision or recommendation would typically be encountered.

\section{Task 4. Select CDS Intervention Type and Develop Interface Wireframe Prototypes}

CDS can be delivered through numerous interventions: these include order sets, reminders, alerts, documentation templates, reference links, and info buttons. ${ }^{18}$ Selecting the appropriate CDS intervention for the recommendation is critical for CDS adoption. ${ }^{18,19}$ The purpose of this task is to identify the CDS intervention best suited to provide CDS recommendations within the EHR, and develop a wireframe prototype of the proposed interface. Creating a wireframe prototype allows local healthcare stakeholders to provide feedback regarding usability to allow optimization of interface design.

Stakeholder teams should work with clinician subject matter experts and practicing clinicians to understand local workflow and the decision making processes. Potential CDS intervention types should then be identified for each clinical phase; the most appropriate intervention should be selected based on clinical workflow requirements. Wireframe prototypes should be developed and reviewed with the appropriate stakeholders to solicit feedback and assess usability.

\section{Task 5. Parse Recommendations and Restructure Content for Encoding}

The purpose of this task is to parse recommendation statements generated in task one and categorize components by target user, decision variable type, and actions. A publicly available 
tool to support this process is the Guideline Elements Model (GEM) software program. The GEM software program, also known as "GEM Cutter”, provides a means to organize, or "cut”, narrative text in the form of guideline recommendations, into concepts, relationships and attributes. ${ }^{20}$ Technical details for this software tool and process are described in the ASTM standard E2210. ${ }^{21}$ In this process, each decision variable is expressed as a Boolean expression (e.g. C. diff infection [true]) or as an enumerated list (e.g. symptoms of abdominal involvement [vomiting, distention, or ileus]). Components are further categorized according to action type (e.g. diagnose, order, refer, laboratory). ${ }^{22}$

This task should be completed by a trained data abstracter. The resulting product should be reviewed by the team to ensure recommended actions derived from the clinical pathway have been accurately interpreted and encoded using standardized terminologies. Structures and data created from this task are used in the next task for assigning and tagging components using standardized terminologies (Task 6), such as LOINC or ICD-10 codes.

\section{Task 6. Meta-Tagging and Creation of Standardized Value Sets}

The process of meta-tagging involves assigning machine readable standardized terminology to concepts within recommendation statements. These standardized terminologies, such as ICD 10, Snomed, LOINC, RxNorm, provide the "vocabulary" necessary for computers to interpret the meaning of any particular item. ${ }^{23,24}$ For instance, if the CDS recommended ordering a CT of the abdomen and pelvis, meta-tagging provides the specific set of standardized codes computers use to describe this particular test. A “value set” encompasses all relevant terms that might be used to describe any particular item or group of items. ${ }^{25}$ The National Library of Medicine's (NLM) supports the Value Set Authority Center (VSAC), ${ }^{25}$ which provides an authoring tool for public value set development and also serves as a repository for value sets. Using such standardized values sets in CDS artifact development is important for supporting consistent interoperable CDS implementation across settings and is required for developing CDS artifacts into clinical quality language (CQL) (Task 7).

To avoid creating redundant value sets, the NLM VSAC should be queried to identify existing value sets that potentially address the "GEM cuts" developed in the previous task. If no adequate existing value sets are identified, new value sets must be created. Value set creation can be completed using web-enabled platforms to support code selection (e.g. VSAC, ${ }^{25}$ $\mathrm{GEM}_{2 \mathrm{QDM}}{ }^{26}$ ). To ensure transparency, facilitate reproducibility, and support future updates, searches used to identify relevant codes within each terminology should be saved alongside the included value set. Furthermore, all value sets should be reviewed by a clinician with domain experience for accuracy. In addition to the reviewing the list of identified codes, reviewers also consider whether the search used to identify relevant terms was appropriate and whether identified codes sufficiently describe the clinical concept.

\section{Task 7. Encode Recommendations Using CQL}

CDS Connect is an AHRQ-funded repository of CDS artifacts created to advance the integration of evidence into clinical practice through the development of standards-based, publicly available, and shareable CDS artifacts. ${ }^{13}$ The purpose of this task is to use the CDS Authoring Tool to develop CQL from the content generated in the previous tasks. 
The CDS Authoring Tool provides an interface for creating CDS machine readable logic using simple forms. Figure 3 shows the tool interface and available forms, which include Inclusion Criteria; Exclusion Criteria; Subpopulations; Base Elements; Recommendation statements; Parameters; and Handling Errors.

Figure 3. CDS connect CQL authoring tool data entry interface

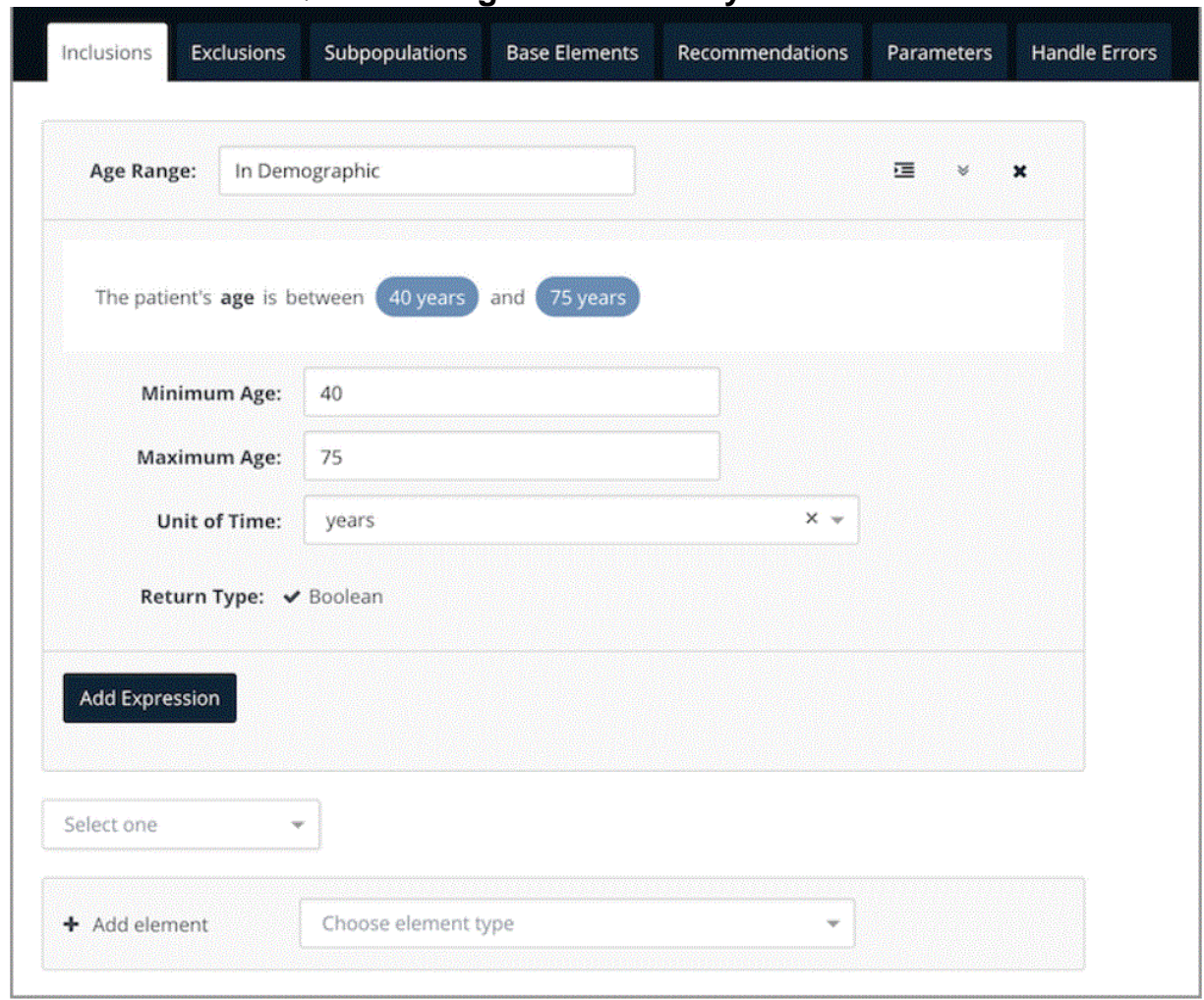

The team should identify relevant forms and use the data created from the previous tasks (i.e. value sets and structured and logical recommendation statements) to produce the CQL code. Final products can be exported for insertion into an EHR or creation of a standalone CDS application such as Health Level Seven (HL7) Clinical Quality Language (CQL) artifacts using the HL7 Fast Healthcare Interoperability Resources (FHIR) data model. ${ }^{16}$ 


\section{Results}

\section{Task 1. Extract Data, Catalog, and Assess for CDS Inclusion Eligibility}

Two team members (JM, AT) extracted 24 decision points and recommendations from the pathway and categorized each statement (task one). Team members familiar with the clinical pathway and a subject matter expert (NM, EF, and LD) reviewed the extracted and categorized recommendation statements for accuracy. Table three (columns one and three) contains a full list of recommendations, categories, and identifiers. Two statements related to pathway inclusion criteria (D1 and D2, Table 3) were excluded from the final recommendation list as they pertained to CDI diagnosis and were addressed in a separate pathway.

Table 3. Recommendation statements extracted from the CDI pathway

\begin{tabular}{|c|c|c|}
\hline Type of Action & Clinical Phase & Recommendation Statement \\
\hline $\begin{array}{l}\text { D1: Pathway } \\
\text { Inclusion }\end{array}$ & Before pathway & $\begin{array}{l}\text { Begin CDI pathway if inpatient, positive C. diff test AND clinical } \\
\text { signs/symptoms consistent with CDI -- excluded }\end{array}$ \\
\hline $\begin{array}{l}\text { D2: Pathway } \\
\text { Inclusion }\end{array}$ & Before pathway & $\begin{array}{l}\text { Begin CDI diff pathway if inpatient and high clinical suspicion (e.g. } \\
\text { fever, high white blood cell count, }>=3 \text { documented liquid stools in } 24 \\
\text { hours) -- excluded }\end{array}$ \\
\hline O1: Stop Antibiotics & $\begin{array}{l}\text { Treatment } \\
\text { Initiation }\end{array}$ & $\begin{array}{l}\text { When starting the CDI pathway, if possible STOP precipitating } \\
\text { antibiotic(s). Discontinue therapy with inciting antibiotic agent(s) as } \\
\text { soon as possible, as this may influence the risk of CDI recurrence. }\end{array}$ \\
\hline O2: Stop Laxatives & $\begin{array}{l}\text { Treatment } \\
\text { Initiation }\end{array}$ & When starting the CDI pathway, if possible STOP laxatives. \\
\hline $\begin{array}{l}\text { O3: Avoid anti- } \\
\text { peristaltic agents }\end{array}$ & $\begin{array}{l}\text { Treatment } \\
\text { Initiation }\end{array}$ & $\begin{array}{l}\text { When starting the CDI pathway, stop and avoid anti-peristaltic agents } \\
\text { (loperamide, Lomotil) throughout treatment course. }\end{array}$ \\
\hline $\begin{array}{l}\text { D3: Diagnose } \\
\text { Recurrent CDI }\end{array}$ & $\begin{array}{l}\text { Treatment } \\
\text { Selection }\end{array}$ & $\begin{array}{l}\text { Diagnose as recurrent CDI if positive C. diff test with recurrent } \\
\text { symptoms attributable to CDI within } 8 \text { weeks of successfully completing } \\
\text { treatment for previous CDI that was associated with interval } \\
\text { improvement. }\end{array}$ \\
\hline $\begin{array}{l}\text { D4: Diagnose } \\
\text { Refractory CDI }\end{array}$ & $\begin{array}{l}\text { Treatment } \\
\text { Selection }\end{array}$ & $\begin{array}{l}\text { Diagnose as refractory CDI if lack of symptomatic improvement to } \\
\text { appropriate prescribed treatment for CDI. }\end{array}$ \\
\hline $\begin{array}{l}\text { C1: Management of } \\
\text { Refractory CDI }\end{array}$ & $\begin{array}{l}\text { Treatment } \\
\text { Selection }\end{array}$ & If refractory CDI is suspected, consider alternative causes for infection. \\
\hline $\begin{array}{l}\text { R1: Management of } \\
\text { Refractory CDI }\end{array}$ & $\begin{array}{l}\text { Treatment } \\
\text { Selection }\end{array}$ & If refractory CDI is suspected, consult infectious disease. \\
\hline $\begin{array}{l}\text { L1: Evaluation, first } \\
\text { episode }\end{array}$ & $\begin{array}{l}\text { Treatment } \\
\text { Selection }\end{array}$ & $\begin{array}{l}\text { If first (i.e. non-recurrent) CDI, obtain OR ensure has obtained within } \\
\text { the last } 24 \text { hours CBC and BMP. }\end{array}$ \\
\hline $\begin{array}{l}\text { D5: Diagnose CDI } \\
\text { Severity Non- } \\
\text { Severe }\end{array}$ & $\begin{array}{l}\text { Treatment } \\
\text { Selection }\end{array}$ & $\begin{array}{l}\text { Diagnose patient presenting with non-recurrent CDI as "CDI, non- } \\
\text { severe" if WBC<15,000 cells/mL AND } \mathrm{Cr}<1.5 \mathrm{mg} / \mathrm{dl} \text {. }\end{array}$ \\
\hline $\begin{array}{l}\text { D6: Diagnose CDI } \\
\text { Severity Severe }\end{array}$ & $\begin{array}{l}\text { Treatment } \\
\text { Selection }\end{array}$ & $\begin{array}{l}\text { Diagnose patient presenting with non-recurrent CDI as "CDI, severe" if } \\
\text { WBC>=15,000 cells } / \mathrm{mL} \text { or } \mathrm{Cr}>=1.5 \mathrm{mg} / \mathrm{dl} \text {. }\end{array}$ \\
\hline $\begin{array}{l}\text { D7: Diagnose CDI } \\
\text { Severity Fulminant }\end{array}$ & $\begin{array}{l}\text { Treatment } \\
\text { Selection }\end{array}$ & $\begin{array}{l}\text { Diagnose patient presenting with non-recurrent CDI as "CDI, fulminant" } \\
\text { if sepsis with acute organ dysfunction OR septic shock OR abdominal } \\
\text { signs/symptoms (vomiting, distention) concerning for ileus, toxic } \\
\text { megacolon. }\end{array}$ \\
\hline $\begin{array}{l}\text { O4: Non-Fulminant } \\
\text { CDI, off Antibiotics }\end{array}$ & $\begin{array}{l}\text { Treatment } \\
\text { Selection }\end{array}$ & $\begin{array}{l}\text { If CDI and not on antibiotics, treat with vancomycin, } 125 \text { mg q6h for } 10 \\
\text { days. }\end{array}$ \\
\hline $\begin{array}{l}\text { O5: Non-Fulminant } \\
\text { CDI, on Antibiotics }\end{array}$ & $\begin{array}{l}\text { Treatment } \\
\text { Selection }\end{array}$ & $\begin{array}{l}\text { If CDI and on antibiotics, treat with vancomycin, } 125 \mathrm{mg} \text { q6h for } 10 \text { days } \\
\text { minimum but consider extending the treatment course for } 7 \text { days } \\
\text { beyond the current course of treatment. }\end{array}$ \\
\hline O7: Fulminant CDI & $\begin{array}{l}\text { Treatment } \\
\text { Selection }\end{array}$ & If diagnosed with fulminant CDI, order a C. diff test to confirm. \\
\hline
\end{tabular}




\begin{tabular}{|c|c|c|}
\hline Type of Action & Clinical Phase & Recommendation Statement \\
\hline O8: Fulminant CDI & $\begin{array}{l}\text { Treatment } \\
\text { Selection }\end{array}$ & $\begin{array}{l}\text { If diagnosed with fulminant } \mathrm{CDI} \text {, abdominal x-ray or CT is } \\
\text { recommended if abdominal signs/symptoms (vomiting, distention) } \\
\text { concerning for ileus, toxic megacolon. }\end{array}$ \\
\hline R2: Fulminant CDI & $\begin{array}{l}\text { Treatment } \\
\text { Selection }\end{array}$ & $\begin{array}{l}\text { If diagnosed with fulminant CDI, surgical and infectious disease } \\
\text { consults are recommended. }\end{array}$ \\
\hline O9: Fulminant CDI & $\begin{array}{l}\text { Treatment } \\
\text { Selection }\end{array}$ & $\begin{array}{l}\text { If diagnosed with fulminant } \mathrm{CDI} \text {, and NO significant abdominal findings } \\
\text { treat with vancomycin } 500 \mathrm{mg} \mathrm{PO} / \mathrm{NG} \text { Q6h x14 days AND } \\
\text { metronidazole } 500 \mathrm{mg} \text { IV Q8H x } 14 \text { days. }\end{array}$ \\
\hline $\begin{array}{l}\text { O10: Fulminant } \\
\text { CDI }\end{array}$ & $\begin{array}{l}\text { Treatment } \\
\text { Selection }\end{array}$ & $\begin{array}{l}\text { If diagnosed with fulminant CDI, and significant abdominal findings treat } \\
\text { with vancomycin } 500 \mathrm{mg} \text { PO/NG Q6h x14 days vancomycin retention } \\
\text { enema } 500 \mathrm{mg} \text { in } 100 \mathrm{~mL} \text { sterile water q6h x14 days AND } \\
\text { metronidazole } 500 \mathrm{mg} \text { IV Q8H x } 14 \text { days. }\end{array}$ \\
\hline M1: Monitoring & $\begin{array}{l}\text { Treatment } \\
\text { Monitoring }\end{array}$ & $\begin{array}{l}\text { If following CDI pathway and no improvement within } 5 \text { days consider } \\
\text { alternative diagnosis and consult infectious disease. }\end{array}$ \\
\hline $\begin{array}{l}\text { O11: First } \\
\text { recurrence }\end{array}$ & $\begin{array}{l}\text { Treatment } \\
\text { Selection }\end{array}$ & $\begin{array}{l}\text { If recurrent CDI and first recurrence then treat with vancomycin } 125 \mathrm{mg} \\
\mathrm{PO} \mathrm{QH} \text { for } 10 \text { days (especially if previously treated with } \\
\text { metronidazole) OR vancomycin tapered regimen (see pathway). }\end{array}$ \\
\hline $\begin{array}{l}\text { O12: Multiple } \\
\text { recurrence }\end{array}$ & $\begin{array}{l}\text { Treatment } \\
\text { Selection }\end{array}$ & $\begin{array}{l}\text { If recurrent CDI and not first recurrence then treat with vancomycin } \\
\text { taper (see pathway), consider infectious disease consult, and consider } \\
\text { fecal microbiota transplantation. }\end{array}$ \\
\hline O13: Stop PPI & $\begin{array}{l}\text { Treatment } \\
\text { Initiation }\end{array}$ & $\begin{array}{l}\text { When starting the C. diff pathway avoid unnecessary proton pump } \\
\text { inhibitors (PPI). }\end{array}$ \\
\hline
\end{tabular}

\section{Task 2. Assess Feasibility and Identify Barriers for Conversion to L3 CDS Artifact}

Each team member completed the eGLIA evaluation for each extracted statement according to the seven domains identified above (Task 2). We did not assess validity within the eGLIA evaluation since the intent of extracted recommendation statements are already incorporated into process for clinical pathway development. The eGLIA assessment was uploaded to the AHRQ CDS Connect site to ensure transparency.

The eGLIA assessment identified several areas of discordance across team members. Several examples discordant statement evaluations requiring resolution are included in Appendix A. Most low scores pertained to executability and lack of actionable detail. For example, the clinical pathway recommended treatment with vancomycin in several situations, but failed to specify what alternative treatment a patient with a vancomycin allergy should receive.

All areas of disagreement were discussed as a group, along with potential mechanisms for resolution. When necessary, recommendation statements were updated typically to provide more clarity. This process also resulted in changes to the original CDI treatment pathway (described in Table 4). Original and updated CDI pathways can be found in Appendix B and C respectively. All modifications to the CDS statements and pathway were reviewed by the two UPHS team members (NM, EF) and the local clinical pathway subject matter experts. Similarly, to improve transparency the updated clinical pathway was also uploaded to the AHRQ CDS Connect website. The revised clinical pathway was published on June 17, 2019 for use within the University of Pennsylvania Health System. 
Table 4. List of clinical pathway changes

\begin{tabular}{|c|l|}
\hline No. & \multicolumn{1}{c|}{ Description of Changes to CDI Pathway } \\
\hline 1 & $\begin{array}{l}\text { Sepsis recognition tool added to assist providers in identifying septic shock and sepsis with acute organ } \\
\text { dysfunction. }\end{array}$ \\
\hline 2 & $\begin{array}{l}\text { Definition for fulminant CDI clarified to emphasize that CDI should be the cause of sepsis with acute organ } \\
\text { dysfunction or septic shock without other identifiable etiology. }\end{array}$ \\
\hline 3 & Management of fulminant CDI moved to the beginning of the pathway for usability. \\
\hline 5 & $\begin{array}{l}\text { Treatment alternatives in the case of intolerance or allergy to vancomycin updated to specify "oral" } \\
\text { vancomycin. }\end{array}$ \\
\hline 6 & $\begin{array}{l}\text { "Monitoring for improvement or changes" updated to specify that providers should monitor changes to } \\
\text { "diarrhea" specifically. }\end{array}$ \\
\hline 7 & $\begin{array}{l}\text { CDI severity node modified to include the definition for fulminant only. Treatment recommendations for } \\
\text { X-ray recommendations for fulminant infection updated to include position and type. Abdominal CT } \\
\text { changed to be a consideration only and updated to include recommendations for intravenous and oral }\end{array}$ \\
\hline 8 & $\begin{array}{l}\text { Fulminant CDI recommendations updated to include treatment of recurrent CDI. Initial CDI recurrence } \\
\text { recommendations are to start a vancomycin taper (similar taper as for the non-fulminant recurrent CDI } \\
\text { case). }\end{array}$ \\
\hline 9 & $\begin{array}{l}\text { Monitoring for fulminant CDI: recommendation added to confer with infectious disease providers if the } \\
\text { patient has significant abdominal findings or slow resolution after treatment has been initiated and to } \\
\text { consider a prolonged treatment course in those scenarios. }\end{array}$ \\
\hline 10 & $\begin{array}{l}\text { Node for laboratory order requirements removed as these were no longer necessary for diagnosing C. } \\
\text { difficile infection severity. }\end{array}$ \\
\hline
\end{tabular}

\section{Task 3. Categorize Recommendation Statements by Clinical Phase}

The team identified the following three clinical workflow phases relevant for this pathway: treatment selection, treatment initiation, treatment monitoring (see Table 3, second column). Two recommendations were related to inclusion criteria (e.g. is the patient relevant for inclusion in this pathway) and were not assigned a clinical workflow phase.

\section{Task 4. Identify Appropriate CDS Intervention Types To Support Implementation of the CDS Artifact and Develop Interface Wireframe Prototypes}

Our team consulted with clinician subject matter experts in infectious diseases and practicing clinicians (hospitalist and infectious disease physician) within UPHS to understand workflow and the decision making process for CDI treatment initiation and selection. Using this information, we identified two CDS interventions, alerts (treatment initiation) and an order set (treatment selection) as most appropriate for this project (see Table 5). However, within the UPHS health system new alert requests are typically reserved for patient safety interventions. As the majority of recommendation statements pertained to treatment selection, the team decided that developing an order set would be best suited to deliver decision support to providers, and would also limit selection of low value treatments (e.g. fidaxomicin for vancomycin tolerant patients). Furthermore, we were also able to incorporate the four recommendation statements pertaining to treatment initiation as text within the order set. 
Table 5. Potential CDS interventions by workflow

\begin{tabular}{|l|l|l|}
\hline \multicolumn{1}{|c|}{ Clinical Phase } & CDS Intervention & \multicolumn{1}{c|}{ Considerations } \\
\hline Initiation of treatment & Alert or Reminder & $\begin{array}{l}\text { Actions during the initiation of treatment phase are primarily } \\
\text { recommendations to STOP medications. In order to address the } \\
\text { asynchronous workflow and to account for needing to avoid these } \\
\text { medications during treatment, it was determined that an alert (if } \\
\text { medications recommended to be stopped were active) and } \\
\text { reminders (when attempting to order the medication to be avoided) } \\
\text { would provide strong support for implementation of these } \\
\text { recommendations. }\end{array}$ \\
\hline Selection of treatment & Order Set & $\begin{array}{l}\text { Selection of treatment is coupled with appropriate determination of } \\
\text { CDI severity and classification (initial episode, first recurrence, or } \\
\text { multiple recurrent). Treatment and evaluation recommendations } \\
\text { were strongly associated with this determination. Additionally, it was } \\
\text { likely that this determination, once made, would not need to be } \\
\text { reassessed for the next several days (in most circumstances). An } \\
\text { order set would provide sufficient support for clinicians to have the } \\
\text { appropriate recommendation information. By clustering orders within } \\
\text { the order set by CDI classification, we believed we could further } \\
\text { support clinicians making the correct selection of order groups. }\end{array}$ \\
\hline $\begin{array}{l}\text { After starting } \\
\text { treatment }\end{array}$ & $\begin{array}{l}\text { Only one action was recommended after selection of treatment: } \\
\text { monitoring. Due to the multiple ways a patient may be considered to } \\
\text { not be improving, the most reasonable mechanism we identified to } \\
\text { encapsulate this recommendation into CDS was through an alert. }\end{array}$ \\
\hline
\end{tabular}

We created a wireframe prototype using Microsoft Word to explore possible features for an order set build within the UPHS Epic EHR environment (in preparation for L4 CDS artifact translation). The final wireframe design is included as Appendix D. ${ }^{13}$ The order set was designed to display only when opened by ordering clinicians. Orders are grouped into panels according to CDI episode classification (i.e. first episode, fulminant episode, first recurrence, and multiple recurrent) and further organized within each panel according to CDI scenario likelihood, with the least likely scenario (i.e. fulminant) listed last. Upon opening the order set, all section panels listed above as possible choices will be displayed; however, details will be collapsed to minimize visual complexity and facilitate quick location of the appropriate clinical scenario. Providers can expand sections to review orders by clicking on the section title. Preferred orders within each clinical scenario would be selected by default to reduce click requirements for providers

At the top of the order set, we included guidance on CDI episode classification, recommendations from the initiation of treatment clinical phase, display of relevant laboratory data, and a link to the CDI treatment clinical pathway. Each order section provides the narrative recommendation text for the clinician (adapted from the pathway). We met with key clinical stakeholders to review the content and design. Minimal changes were required during the review phase of the order set prototype.

Several aspects of our CDS wireframe design as intended to optimize usability. To reduce the number of clicks required to place orders, preferred treatments for each panel are already preselected. Thus, our final design allows treatments for most clinical scenarios to be ordered using two clicks or less. Also, treatment alternatives (e.g. for intolerance to oral vancomycin) are embedded within each clinical scenario. Although this creates some redundancy within the order set, this approach reduces the amount of searching and scrolling required by each individual user, which we believe will improve usability. To drive order set use, once implemented, ordering providers will be required to order CDI treatments using this order set. Furthermore, all selections can be changed at the discretion of the provider without any hard stops by unselecting choices within each order panel. 
The Penn Medicine Center for Evidence-based Practice has submitted a request to information services within UPHS to implement the CDI treatment algorithm recommendations in a UPHS system-wide inpatient order set. The proposed order set will be reviewed by the UPHS antimicrobial sub-committee of pharmacy and therapeutics for approval. We anticipate an expedited review process as many of the stakeholders for this project are also sub-committee members. After approval, the order set will be reviewed by information services, the clinical decision support committee, and potentially others such as the inpatient and technical committees.

\section{Task 5. Prepare Content for Encoding}

The clinical pathway and statements listed in Table 3 were used as input for encoding. A trained abstractor (JM) used the GEM software program to parse and encode content. Clinical pathway statements had up to 5 trigger conditions (GEM decision variables) and up to 3 recommended actions, which were either intended to be performed together or were potential alternatives. Each clinical pathway statement could be expressed using a simple Boolean logic statement (i.e. if $\mathrm{X}$ and $\mathrm{Y}$, then do Z). Because the clinical pathway was focused on a specific set of clinical scenarios, a relatively limited subset of GEM elements were necessary for encoding relevant clinical content.

The final content set was reviewed with the team for accuracy and completeness. Selected sections of the GEM cut are available in Appendix E and have been published on the AHRQ CDS Connect site. ${ }^{13}$ The final GEM report provides a reference for CDS developers or quality measure developers looking to utilize this clinical pathway to create their own machine executable representations of the UPHS CDI treatment pathway.

\section{Task 6. Meta-Tagging and Creation of Standardized Value Sets}

The GEM report generated in in the previous task was used as the primary input for this step to drive the development of value sets (Task 6). We first queried the NLM VSAC to identify existing relevant value-sets and identified three relevant value sets for describing laxatives and stool softeners, IV vancomycin, and sepsis:

• $\quad$ "Stool softeners and laxatives VS": '2.16.840.1.113762.1.4.1032.44'

o Contains a list of medications used as stool softeners and laxatives (e.g. docusate, glycerin)

o Maintained by MITRE for associated quality measures

• "Sepsis VS": '2.16.840.1.113883.17.4077.3.2033'

o Contains a list of clinical conditions that would be considered

o Maintained by the American College of Emergency Physicians/AMA-PCPI

• "IV Vancomycin VS": '2.16.840.1.113883.3.666.5.766'

o Contains two codes for IV vancomycin

o Maintained by Lantana

o Used to assist with allergy checking

After careful review, we determined these value sets were adequate for incorporation into our project without modification.

We created an additional 61 new value sets to represent the remaining clinical concepts extracted from the pathway. All new values sets, including their search parameters, were 
published on the VSAC site. ${ }^{27}$ All value sets created during this project list ECRI Institute as both steward and author. The value set created for C.difficile infection can be found in Appendix F.

Development of the new value sets was completed by two members of our team (JM, AT) and members of the ECRI Guidelines Trust (EGT). We used the web-based GEM2QDM tool ${ }^{26}$, which was populated with the GEM report data, to "meta-tag" each unique clinical concept identified during GEM cutting. Two clinicians not involved in the value set development (NM and LD) reviewed the content to assess the performance of the search algorithm and whether the value set appropriately represented the concept. Four distinct codes in three different value sets were identified as clinically inappropriate (e.g. related to pediatric indications when the pathway is only applicable to adults). These codes were subsequently removed from the final file. During the review process one code was added to a Snomed based value set for the clinical concept “Computed tomography (CT) abdomen.” While reviewing initial versions of the value set, we noticed the absence of a code for 'CT of abdomen with contrast.' Initial attempts to identify this term within the Snomed code set were unsuccessful. On review, we discovered the term was inappropriately named "Computerised tomography" in Snomed-CT rather than "Computed tomography," which is used for all other CTs. ${ }^{27}$ We added this code to the value set list and reported this discrepancy to the clinical terminology owner for correction.

\section{Task 7. Encode Recommendations Using CQL}

The CDS Authoring Tool supports the encoding of clinical content in several forms/formats. Four forms were identified as relevant to our content for CQL encoding using the CDS Authoring Tool: inclusion criteria, subpopulations, base elements, and recommendations (Table 6). The concept of $C$. difficile infection was encoded as an inclusion criterion. The other concepts represented in GEM as decision variables (i.e. triggers) were encoded as subpopulations. Fifteen subpopulations (e.g. “On Laxatives”, "Recent CDI Infection”) were needed to express the decision nodes. Three of these subpopulations were inverses of other subpopulations, as the CQL authoring tool does not yet support negation of subpopulations. For example, for recommendations related to laxatives, it was necessary to develop subpopulations for “On Laxatives" and "Not on Laxatives”. Some decision variables were combined or grouped using CQL to create compound statements. The CQL representations contained between one and five of the base GEM concepts. GEM actions were expressed as base elements, and encoded within CQL with a similar level of statement complexity (between one and five clinical concepts per statement). The logic on when to have each action occur was encoded using the recommendation forms. A single subpopulation, or in six instances two subpopulations, was linked to each action through the recommendations.

Table 6. CQL CDS authoring tool forms and descriptions

\begin{tabular}{|l|l|}
\hline \multicolumn{1}{|c|}{ CQL Authoring Form } & \multicolumn{1}{c|}{ Description } \\
\hline Inclusion criteria & Describe the default population for which the CDS could be relevant \\
\hline Subpopulations & $\begin{array}{l}\text { Describes characteristics of patients who meet the inclusion criteria for which a } \\
\text { particular portion of the CDS is actually relevant }\end{array}$ \\
\hline Base elements & $\begin{array}{l}\text { Provide a building block for developing inclusion criteria and/or subpopulations that } \\
\text { share reusable components }\end{array}$ \\
\hline Recommendations & $\begin{array}{l}\text { Provide a mechanism for communicating what should happen when a particular } \\
\text { combination of subpopulations is identified }\end{array}$ \\
\hline
\end{tabular}

As the CDS Authoring Tool is in early stages of development, not all possible permutations of CQL encoding were supported. Consequently, some recommendations for the clinical 
management of CDI could not be completely expressed. ${ }^{28}$ Table 6 lists the authoring exceptions that were encountered during this process and the subsequent resolution.

Additionally, we found that value set encoded actions are not yet supported within the CDS Authoring Tool. At present, the code produced by the CDS Authoring Tool only provides guidance statements, and cannot trigger an order within an EHR. Therefore, actions were encoded as text recommendations, and within each recommendation guidance was provided for how the recommendation should be made executable. For example, within the CQL recommendation triggered in patients with recurrent CDI and previous metronidazole use, the text statement reads Order Vancomycin as first line $125 \mathrm{mg}$ PO q6h x 10 days (Base Element = Vancomycin PO). By indicating the Base Element to be used in future CQL iterations, we are providing a pathway for the development of CQL than can trigger orders within an EHR. A summary of issues encountered during CQL encoding and their resolution is provided in Table 7.

Table 7. Summary of issues encountered during CQL encoding using the CDS authoring tool and their resolution

\begin{tabular}{|c|c|}
\hline $\begin{array}{r}\text { Issue } \\
\end{array}$ & Comment/Handling \\
\hline $\begin{array}{l}\text { Vancomycin Enema (no code) } \\
\text { Vancomycin Taper Regimen } \\
\text { (no code) }\end{array}$ & $\begin{array}{l}\text { Currently pointing to the vancomycin non-injectable order set as a place holder. } \\
\text { This is consistent with the RxNorm use of vancomycin oral formulation } \\
\text { delivered rectally and the use of the oral formulation for the taper regimen. As } \\
\text { these relate to executable orders, they would need to be further defined in } \\
\text { specific local settings. }\end{array}$ \\
\hline $\begin{array}{l}\text { No mechanism to specify } \\
\text { temporal relationships } \\
\text { Not possible to check to see } \\
\text { duration of condition with } \\
\text { current expressions. }\end{array}$ & $\begin{array}{l}\text { When trying to determine if there is a recurrence we needed to identify if a CDI } \\
\text { had occurred within the past } 28 \text { days and had subsequently resolved. } \\
\text { Translation of 'episodes of care' in QDM into CQL encoding is not yet } \\
\text { supported in the CDS Authoring Tool. The suggested way to encode this is } \\
\text { using "look back" periods. However, it is currently not possible to specify a } \\
\text { beginning of the look back period and the default beginning is NOW. This would } \\
\text { result in all patients with a CDI diagnosis in the past } 24 \text { hours being included as } \\
\text { recurrent. For now, we have included this as a comment for local implementers. }\end{array}$ \\
\hline $\begin{array}{l}\text { Not possible to obtain an } \\
\text { occurrence count of observation } \\
\text { within a lookback time. }\end{array}$ & $\begin{array}{l}\text { We attempted to express the concept of multiple episodes of loose stool within } \\
\text { a } 24 \text { hour look back period. While we could use the look back period and } \\
\text { occurrence counter separately, these could not be combined. A comment was } \\
\text { included for local implementers. }\end{array}$ \\
\hline $\begin{array}{l}\text { Subpopulations cannot be } \\
\text { linked as OR groups } \\
\text { Negation of subpopulations } \\
\text { cannot be used to inform } \\
\text { recommendations }\end{array}$ & $\begin{array}{l}\text { Several combinations of decision variables lead to a shared recommended } \\
\text { action in addition to separate specific recommendations. To achieve parsimony } \\
\text { and simplify updates it would be necessary to have this recommendation } \\
\text { triggered using an OR clause on subpopulations, however this is not yet } \\
\text { supported. Similarly, in some instances there were recommendations that } \\
\text { applied if a subpopulation was TRUE while others applied if that subpopulation } \\
\text { was FALSE. Ideally, we would be able to negate the TRUE subpopulation, but } \\
\text { that is not yet supported. To address this, we created two copies of the } \\
\text { subpopulation (one true and one false). This will impact maintenance of the } \\
\text { CQL artifact. }\end{array}$ \\
\hline
\end{tabular}

\section{Summary of Final Work Products}

Two primary work products developed as a result of this project were (1) L3 CDS artifact translated from the clinical pathway for CDI treatment (L2) and (2) CDS wireframe user interface prototypes that could be used to implement the CDS within a healthcare setting to achieve L4 CDS artifact development. These are available on the AHRQ CDS Connect site. ${ }^{13}$

As a result of this project, we also developed three secondary products that we anticipate will be of interest to the CDS development community, clinicians, and health system leadership:

1. Updated C. difficile treatment pathway - disseminated throughout UPHS and available on the AHRQ CDS Connect site ${ }^{13}$ 
2. GEMified representation of the pathway (Task 5) - available on the AHRQ CDS Connect site $\mathrm{e}^{13}$

3. C. difficile treatment value sets (Task 6) - available on the VSAC site ${ }^{27}$ 


\section{Discussion}

Using a systematic approach and an existing, trustworthy evidence-based clinical pathway to develop a shareable CDS artifact offers one method for improving large-scale translation and dissemination of evidence into health systems and clinical practice. The purpose of this ECRI Institute-Penn Medicine EPC methods project was to use a systematic approach to translate a previously developed evidence-based clinical pathway (L2) for C. difficile infection (CDI) treatment ${ }^{29}$ into a structured (L3) artifact and to identify an optimal CDS intervention type in which to implement recommendations, using the UPHS EHR environment as an exemplar.

Below, we outline 4 lessons learned for other health systems seeking to develop or adapt CDS artifacts associated with the AHRQ EPC program. Overall, our pilot demonstrated that using a trustworthy evidence-based clinical pathway to create machine-readable L3 CDS is feasible and can be used by health systems as a method for integrating evidence into clinical practice.

\section{Lessons Learned}

\section{Lesson 1: Publicly Available Software for Translating Guideline Recommendations Into CDS Can Be Used To Create and Maintain Trustworthy CDS Artifacts From Clinical Pathways}

We leveraged publically available technology for translating guideline recommendations into CDS. Specifically eGLIA, GEM, the VSAC, and the CDS Authoring Tool, ${ }^{17,25,28,30}$ were used to translate recommendations in the CDI treatment clinical pathway into a machine-readable L3 CDS. Our findings demonstrate that using existing tools is feasible and an approach other institutions can use to create CDS artifacts adapted for local settings.

These publically available tools support a transparent and reproducible process that preserves fidelity to evidence. Reports and products generated throughout the process (eGLIA assessments, GEM reports, and value sets) are produced using a well-described process and logged to record how each pathway statement was translated in each task. ${ }^{26}$ If desired, other CDS developers can review our approach and interim products to assess trustworthiness of the process and final product.

Our approach also allows CDS artifacts to be revised in response to changes in the evidence base or environmental changes that require reassessment of CDS implementation. ${ }^{31}$ For instance, standardized clinical terminologies such as RxNorm (for medications) from which the value sets are created undergo weekly, monthly, and annual updates. ${ }^{27,32-34}$ By retaining the search algorithm used in the development of each of these value sets, this systematic process supports ongoing updates.

\section{Lesson 2: Early and Continuous Collaboration Between Subject Matter Experts and Clinical Informaticists Improved Clinical Accuracy and Usability of the Final CDS End Products}

Early and frequent involvement of subject matter experts, CDS developers, and CDS end users in our process was critical to quickly resolve clinical questions as they arose. The collaboration was instrumental in assuring the clinical accuracy of the final L3 CDS artifact and 
L4 CDS interface prototype. We initiated this project by assembling a small but representative team, with involvement from a UPHS infectious disease fellowship trained physician, a physician informaticist, a UPHS physician CDS end user, and the UPHS clinical pathways program manager. During the development of this CDS, we identified several opportunities for inadvertently introducing error into the intermediate products, which may result in errors in the final product. For instance, identifying the most appropriate standardized term to use for mapping recommendation statements can be challenging (Task 6). Input during the mapping process and quality review by a UPHS clinician CDS user and UPHS clinical pathway manager was critical to ensure mappings were clinically appropriate.

Input from UPHS clinicians and clinical end users on our team was also invaluable to inform our pragmatic understanding of clinical workflow and impact of potential order set interfaces. Early usability feedback from these team members pushed our team to consider alternative CDS order set designs, such as grouping recommended orders by clinical scenario (e.g. first CDI episode, non-fulminant). These clinical users were also able to provide phrasing to capture recommended actions that was concise, understandable, and actionable.

Involvement from a physician informaticist, experienced in the technical approach as well as clinical practice, was critical in helping to maintain the clinical reliability of the L3 CDS artifact and interface. While clinicians can resolve areas of clinical ambiguity, most clinicians lack informatics training or experience necessary to perform many of the processes we utilized in developing an L3 CDS artifact (e.g. parsing and encoding recommendations (Task 5), metatagging, creating value sets (Task 6), and encoding CQL (Task 7). This technical knowledge regarding general CDS considerations and typical feasibility challenges was also critical during discussions of workflow and CDS design (Tasks 3 and 4).

We recognize the opportunity to assemble a team which included a trained physician informaticist and clinical subject experts may represent a barrier in our described process given the paucity of trained informaticists and the time constraints of typical clinicians. This may limit the generalizability of our approach, particularly for organizations that lack access to individuals with these particular skills. However, the lack of such specialized expertise at many organizations merely reinforces the need for development of shareable CDS as many organizations will be unable to develop CDS on their own.

\section{Lesson 3: Utilizing an Iterative Development Process Improved the Quality of the Source CDI Treatment Pathway and Interim CDS Products}

Our development methodology incorporated tenets from the agile systems development lifecycle (SDLC), a development model used by software development industry that entails accounting for time and associated steps to make small, quick adjustments iteratively throughout the development of the application, ${ }^{35,36}$ Agile development methods are especially beneficial in complex and rapidly changing environments and have been shown to decrease development time and improve overall quality of the final products. ${ }^{37}$ For example, during the eGLIA evaluation (Task 2) and GEM cutting (Task 5) we identified several areas of ambiguity, gaps, and redundancies within the CDI clinical pathway that would benefit from more clarity. Identifying and addressing these issues early on allowed us avoid having to redo work (e.g. recreation of value sets) to incorporate these clarifications at later stages. In keeping with this approach, we reserved time for updating the CDI treatment pathway to address the identified issues (Table 4). 
We also used this approach in developing the order set template, in iterative consultation with clinical subject matter experts, clinical teams, and the UPHS informatics team.

\section{Lesson 4: Developing an L3 CDS Artifact From a Trustworthy Evidence-Based Clinical Pathway Offered Efficiency Gains}

Developing electronic decision support from clinical practice guidelines can present characteristic challenges. Clinical practice guidelines are often not primarily concerned with considering all clinically relevant permutations of a clinical scenario when creating recommendations. However, this is necessary step when translating recommendations into clinical practice and electronic decision support. Guidelines may also be verbose, and authors may limit the use of redundant phrasing (to make the narrative less repetitive for readers). However, using alternative wording to represent the same action may introduce unnecessary confusion regarding what action is being recommended. Finally, typically, only a subset of the recommendations are useful for an L3 CDS artifact due to factors such as recommendation statements lacking sufficient clarity to be actionable.

We used an existing CDI treatment pathway developed as part of a previous ECRI InstitutePenn Medicine AHRQ EPC methods project as the basis for this methods project. ${ }^{29}$ During the clinical pathway development process, the team incorporated several design principles proposed by Lawal et al. ${ }^{38}$ that expedited our team's initial steps for L3 CDS development. We incorporated timeframes and criteria based progression, used concise statements to detail steps in care, and organized the pathway representation into algorithm format by treatment scenarios that account for local workflows and structures.

As a byproduct of developing the pathway, pathway authors had already completed several components of the CDS design process. These included identifying relevant guideline recommendations for clinical care, adapting recommendations into locally actionable statements, and evaluating the strength of recommendations. As part of developing the CDI treatment pathway, all likely patient scenario combinations (i.e. treatment for both "recurrent" and "fulminant" CDI) had been considered, effectively reducing the work required for our current methods project. In contrast to typical guideline recommendations, we found clinical pathway content was almost universally translatable into CDS logic. Furthermore, because most of the clinical pathway addressed single clinical scenarios, this allowed for more streamlined development of value sets. Within the clinical pathway, most concepts were architecturally expressed the same way each time, making it easier to coordinate the decision variables in GEM and the resultant CDS. The pathway's algorithm format also facilitated identification of criteriadependent decision variables needed to trigger a clinical action (which must often be assumed in isolated clinical guideline recommendation statements.) Thus, we believe that using a clinical pathway as the basis for L3 CDS development provided significant efficiency gains. 


\section{Applicability to AHRQ EPC Program}

\section{Creating CDS From EPC Report-Informed Clinical Pathways Can Promote Widespread Dissemination of Evidence Into Clinical Practice and Support AHRQ's Learning Health System Initiatives}

Increasing use and dissemination of EPC reports to improve patient care is a longstanding challenge and one of the initiatives of the AHRQ EPC program's Learning Health Systems initiative. ${ }^{39}$ One objective of this initiative is development of products and tools to help health systems use findings from EPC reviews. The ECRI Institute-Penn Medicine EPC advanced work begun in prior methods projects by using the AHRQ EPC report on Early Diagnosis, Prevention, and Treatment of $C$. difficile to inform development of the CDI treatment clinical pathway. In this project we have advanced that work even further by developing an L3 CDS artifact and accompanying CDI treatment interface prototype ready for implementation into the UPHS EHR. This project demonstrates one approach for utilizing evidence from EPC reports to support integration of evidence into patient care. We suggest that the AHRQ EPC program consider working with health systems to identify other EPC reports that could be used to guide development of evidence-based clinical pathways and electronic CDS.

As previously noted, this project benefited from a core team representing important key areas of expertise including clinical informatics, guideline and evidence synthesis methodology, clinical subject matter experts, and CDS end-users at the local institutions. However, many organizations may not have access to this type of expertise. To support future translation of EPC reports into trustworthy clinical pathways and electronic CDS, ongoing investment in clinical informaticist training programs will be important.

\section{EPC Reports Should Include Summaries of Existing Guidelines To Improve Efficiencies for Clinical Pathway Development}

To facilitate development of clinical pathways and electronic CDS, summaries of relevant existing high quality guidelines should be included in EPC reports. Including guideline summaries could also provide helpful context for EPC report readers, informing them about current recommendations, and allowing readers to interpret report findings in the context of existing clinical guidance.

\section{Developing a CDI Treatment Quality Measure May Demonstrate Use of AHRQ EPC Reports To Support Quality Improvement Programs for Health Systems}

Much of the work necessary to design and develop a quality measure has already been performed in developing this electronic CDS. This includes the development of value sets, identification of inclusion/exclusion criteria, and measurable actions. CQL was designed specifically to support both CDS and quality measure development, and thus is uniquely suited to support this work. ${ }^{16}$ A future methods pilot building on this work to develop a quality measure for CDI treatment may be beneficial. Development and piloting of such a tool within a health system such as Penn Medicine could allow this work to support quality improvement efforts in health systems and identify important barriers for future developers. Outcomes and process of 
care data from implementing such work might also identify possible improvements to optimize the CDI treatment CDS we developed as well.

\section{Improved Standards for Interoperability and Public Investment in the Development of Shareable CDS Artifacts Create Opportunities for Widespread CDS Use and Adaptation}

Recent progress has been made to improve interoperability for health information technology and to support the use of standards in CDS development. ${ }^{12,16,40-42}$ These advances helped to support creation of the first national, publicly accessible CDS repository: CDS Connect. ${ }^{13} \mathrm{We}$ believe continued support for this resource will support efforts to improve dissemination of evidence-based trustworthy CDS. We are already aware of another site working to implement the CDI treatment pathway locally after identifying it as relevant for their institution.

CDS Connect artifacts support local implementation efforts and are not restricted to a single vendor (i.e. only EPIC). ${ }^{13}$ Other options for disseminating CDS include vendor frameworks and cloud based technologies. ${ }^{43-45}$ While promising, vendor supported mechanisms have significant limitations. For instance, cloud-based systems do not inherently support customization or local workflows, which may impact implementability. Therefore, we believe the CDS Connect repository is an optimal location for shareable CDS artifacts generated from evidence-based reports.

\section{Future Research and Projects}

\section{Enhancements to CDS Connect and the CDS Authoring Tool Can Improve Clinical Accuracy and Expand Adaption of CDS Artifacts by a Wider Audience}

AHRQ's CDS Connect repository has made important contributions toward the dissemination of shareable CDS L3 artifacts by standardizing the CDS artifact publishing process, providing a curated and publically available site for hosting content, and providing a CDS Authoring Tool, which supports CQL encoding. However, we noted particular issues that if addressed could enhance usability and uptake by CDS authors and users seeking to identify existing CDS for potential implementation at their local institution.

For authors, the CDS Authoring Tool has several strengths: for instance, it successfully suppresses technical complexity for writing CQL logic, which expands access to non-technical writers. However, exclusively using the CDS Authoring Tool did not allow for testing of all aspects of the CQL or encoding logic to the extent we felt necessary for clinical implementation. Ideally, to verify accurate encoding and logic, CDS prototypes should be tested (e.g. using a variety of dummy patient profiles) to assess if a CDS is performing as expected. To facilitate testing, it would have been beneficial to have an array of already developed patients or to be able to generate patients directly within the CDS Authoring Tool for all possible combinations of inclusion criteria. Similarly, for logic expression, as previously noted the CDS Authoring Tool does not yet directly support ordering of tests or medications within an EHR. While CQL can inform a clinician to perform an action, it cannot yet select an action to perform. This limited our ability to assess many things, such as whether the value sets we created behaved as expected. 
Furthermore, at present the tool only allows a limited number of combinations of expressions for CQL statements. For example, it was impossible to code for a stool occurrence count concurrently with a look back period for a single element (i.e. three episodes of diarrhea within the past 24 hours). Similarly, it is difficult to express certain timeframes using the Authoring Tool, which are needed to determine CDI recurrence status and treatment failures. Using the CDS authoring Tool, we could look back to determine if CDI had been diagnosed within the past week, but could not determine if CDI had been diagnosed in the past month, but not in the past week.

CDS Connect was intended to be a resource for users, looking to identify CDS which could be adapted for use at their local institution. To increase adaptation of CDS artifacts by a wider audience (i.e. clinicians, quality and system leaders, and other non-technical staff), we recommend development of standardized, user friendly documentation to provide (1) a high level description of the CQL CDS artifact, (1) the healthcare problem it addresses, (3) clinical roles involved in the development of the artifact; and (4) potential outcomes and metrics.

\section{Development of Tools and an Environment for Conducting End User L3 and L4 Artifact Testing To Assess Fidelity To Source Evidence-Based Recommendations Is Needed}

To ensure fidelity of the final L3/L4 CDS product to the original clinical recommendations and clinical intent, we recommend that end-user focused testing scenarios and test scripts be incorporated into L3/L4 artifact packages for use by clinical subject matter experts to validate that evidence-based recommendations and content has been accurately incorporated into the final artifact. In the software development lifecycle, this stage of testing is often referred to as "black box" testing or "validation and verification." 46 Ideally, CDS artifact testing would be conducted before an artifact is published and made available for general use. This step is especially important since as our experience demonstrated that there are a number of points in the process where errors may inadvertently be introduced. The CDS Connect Authoring Tool provides support for unit testing (testing of combinations of patient characteristics which can be compared to expected system output), but currently, there is no method to test how CDS would function under real world conditions and local EHR environments. We recommend that AHRQ consider developing an EHR testing environment to facilitate testing and quality assurance by prospective clinical users and CDS artifact developers.

\section{Validated Instruments for Trustworthiness of Decision Support (and Evidence Sources) Are Needed To Promote Selection and Evaluation of Shareable CDS}

The AHRQ CDS Connect initiative aims to develop interoperable, EHR agnostic artifacts that can be shared across healthcare settings. Widespread use of these artifacts has the potential to impact care not only at the health system level, but also nationally. However, we anticipate that before considering adaptation, health systems will understandably wish to assess the CDS quality and trustworthiness of the development process. Thus, trustworthiness of the CDS development process will be critical in efforts to increase adaptation. A first step towards providing this assurance for potential users would be for CDS developers to assess the trustworthiness of their source evidence summaries using validated tools, such as the 
Trustworthy Appraisal Scale ${ }^{47}$ for clinical practice guidelines and AMSTAR $2^{48}$ for systematic reviews. These ratings could be uploaded to CDS Connect and made available for potential users. Our project demonstrated that clinical pathways can offer a viable alternative for CDS artifact development that provides significant efficiency gains. However, currently, no validated tools exist for assessing the trustworthiness of clinical pathways. Thus, development of a pragmatic CDS trustworthiness instrument, analogous to instruments created based on the IOM standards for trustworthy guidelines is critical. ${ }^{49,50}$ Such a tool is currently under development at the Penn Medicine Center for Evidence-based Practice. 


\section{Conclusions}

This methods project demonstrated the feasibility of developing an L3 CDS artifact and L4 interface prototype based on an evidence-based clinical pathway using publically available tools and a systematic and transparent approach. This approach offers tremendous potential for creation of shareable CDS artifacts which can be disseminated at the national level. However, several important enhancements are required to improve usability of the CQL CDS Authoring Tool. Furthermore, development of tools for assessing the trustworthiness of various forms of CDS (including clinical pathways) is critical to promote adaptation and uptake. Continued investment by AHRQ in resources such as CDS Connect and support for CDS development work have the potential to improve widespread adoption of evidence-based tools in the EHR. 


\section{References}

1. Van de Velde S, Kunnamo I, Roshanov P, et al. The GUIDES checklist: development of a tool to improve the successful use of guideline-based computerised clinical decision support. Implementation science : IS. 2018 Jun 25;13(1):86. PubMed PMID: 29941007. PMCID: 6019508. Epub 2018/06/27. eng.DOI:10.1186/s13012-018-0772-3

2. Boaz A, Baeza J, Fraser A. Effective implementation of research into practice: an overview of systematic reviews of the health literature. BMC research notes. 2011;4(1):212. PubMed PMID: 21696585. PMCID: 3148986. Epub 2011/06/24. Eng.DOI:10.1186/1756-05004-212

3. Sittig DF, Wright A, Osheroff JA, et al. Grand challenges in clinical decision support. Journal of biomedical informatics. 2008 Apr;41(2):38792. PubMed PMID: 18029232. PMCID: 2660274. Epub 2007/11/22. eng.DOI:10.1016/j.jbi.2007.09.003

4. Poon EG, Blumenthal D, Jaggi T, et al. Overcoming the Barriers to the Implementing Computerized Physician Order Entry Systems in US Hospitals: Perspectives from Senior Management. AMIA 2003 Symposium Procedings. 2003:1.

5. Forrest CB, Fiks AG, Bailey LC, et al. Improving Adherence to Otitis Media Guidelines With Clinical Decision Support and Physician Feedback. Pediatrics. 2013 March 11, 2013.DOI:10.1542/peds.2012-1988

6. Ash JS, Sittig DF, Dykstra R, et al. Identifying best practices for clinical decision support and knowledge management in the field. Studies in health technology and informatics. 2010;160(Pt 2):806-10. PubMed PMID: 20841797. Epub 2010/09/16. eng

7. Bell LM, Grundmeier R, Localio R, et al. Electronic health record-based decision support to improve asthma care: a cluster-randomized trial. Pediatrics. 2010 Apr;125(4):e770-7. PubMed PMID: 20231191. Epub 2010/03/17. eng.DOI:10.1542/peds.2009-1385
8. Heselmans A, Van de Velde S, Donceel P, et al. Effectiveness of electronic guideline-based implementation systems in ambulatory care settings - a systematic review. Implementation science : IS. 2009;4:82. PubMed PMID: 20042070. PMCID: 2806389. Epub 2010/01/01. eng.DOI:10.1186/1748-5908-4-82

9. Middleton B, Sittig D, Wright A. Clinical decision support: a 25 year retrospective and a 25 year vision. Yearbook of medical informatics. 2016;25(S 01):S103-S16.

10. Field TS, Rochon P, Lee M, et al. Costs associated with developing and implementing a computerized clinical decision support system for medication dosing for patients with renal insufficiency in the long-term care setting. Journal of the American Medical Informatics Association. 2008;15(4):466-72.

11. Wright A, Sittig DF, Ash JS, et al. Clinical decision support capabilities of commerciallyavailable clinical information systems. Journal of the American Medical Informatics Association : JAMIA. 2009 Sep-Oct;16(5):637-44. PubMed PMID: 19567796. PMCID: 2744714. Epub 2009/07/02. eng.DOI:10.1197/jamia.M3111

12. Mandel JC, Kreda DA, Mandl KD, et al. SMART on FHIR: a standards-based, interoperable apps platform for electronic health records. Journal of the American Medical Informatics Association : JAMIA. 2016 Feb 17. PubMed PMID: 26911829. Epub 2016/02/26. Eng.DOI:10.1093/jamia/ocv189

13. Agency for Healthcare Research and Quality (AHRQ). CDS Connect: U.S. Department of Health \& Human Services; 2017. Available from: https://cds.ahrq.gov/

14. Agency for Healthcare Research and Quality (AHRQ). Clinical Decision Support: U.S. Department of Health \& Human Services; 2017. Available from: https://healthit.ahrq.gov/ahrqfunded-projects/current-health-itpriorities/clinical-decision-support-cds 
15. Boxwala AA, Rocha BH, Maviglia S, et al. A multi-layered framework for disseminating knowledge for computer-based decision support. Journal of the American Medical Informatics Association : JAMIA. 2011 Dec;18 Suppl 1:i132-9. PubMed PMID: 22052898. PMCID: 3241169. Epub 2011/11/05. eng.DOI:10.1136/amiajnl-2011-000334

16. HL7 Standard: Clinical Quality Language Specification, Release 1 STU3 (CQL 1.3). Health Level Seven International; 2018.

17. Shiffman RN, Dixon J, Brandt C, et al. The GuideLine Implementability Appraisal (GLIA): development of an instrument to identify obstacles to guideline implementation. BMC medical informatics and decision making. 2005;5(23):1-8.DOI:10.1186/14726947-5-23

18. Osheroff JA, Teich J, Levick D, et al. Improving Outcomes with Clinical Decision Support: An Implementer's Guide Healthcare Information and Management Systems Society: HIMSS; 2012.ISBN:1938904206

19. Sirajuddin AM, Osheroff JA, Sittig DF, et al. Implementation pearls from a new guidebook on improving medication use and outcomes with clinical decision support. Effective CDS is essential for addressing healthcare performance improvement imperatives. Journal of healthcare information management : JHIM. 2009 Fall;23(4):38-45. PubMed PMID: 19894486. PMCID: 3316472. Epub 2009/11/10. eng

20. Michel G. GEM Cutter II. Yale Center for Medical Informatics; 2007.

21. ASTM. Standard Specification for Guideline Elements Model version 3 (GEM III)Document Model for Clinical Practice Guidelines. West Conshohocken, PA: ASTM International; 2012.351

22. Essaihi A, Michel G, Shiffman RN. Comprehensive categorization of guideline recommendations: Creating an action palette for implementers. AMIA Annu Symp Proc. 2003:220-4.

23. Samadian S, McManus B, Wilkinson MD. Extending and encoding existing biological terminologies and datasets for use in the reasoned semantic web. Journal of biomedical semantics. 2012;3(1):6. PubMed PMID: 22818710. PMCID: 3639885. Epub 2012/07/24. eng.DOI:10.1186/2041-1480-3-6
24. Olsen J, Baisch MJ. An integrative review of information systems and terminologies used in local health departments. Journal of the American Medical Informatics Association : JAMIA. 2014 Feb;21(e1):e20-7. PubMed PMID: 24036156. PMCID: 3957385. Epub 2013/09/17. eng.DOI:10.1136/amiajnl-2013-001714

25. National Library of Medicine. Value Set Authority Center: National Library of Medicine; 2012 updated 7/16/2016. Available from: https://vsac.nlm.nih.gov/

26. Michel J. Aligning Guidelines Recommendations with Clinical Quality Measures. New Haven: Yale University; 2013

27. International Health Terminology Standards Development Organisation (IHTSDO). SNOMED CT. International Health Terminology Standards Development Organisation.949

28. Agency for Healthcare Research and Quality (AHRQ). CDS Authoring Tool: U.S. Department of Health \& Human Services; 2017. Available from: https://cds.ahrq.gov/cdsconnect/authoring

29. Flores E, Jue J, Giradi G, et al. Use of a Clinical Pathway to Facilitate the Translation and Utilization of AHRQ EPC Report Findings. (Prepared by the ECRI Institute-Penn Medicine Evidence-based Practice Center under Contract No. 290-2015-0005-I.) AHRQ Publication No. 19-EHC002-EF. Rockville, MD: Agency for Healthcare Research and Quality; December 2018. DOI: https://doi.org/10.23970/AHRQEPCMETHENG AGECLINICAL

30. Hajizadeh N, Kashyap N, Michel G, et al. GEM at 10: A decade's experience with the Guideline Elements Model. AMIA Annu Symp Proc. 2011:520-9.

31. Michel J, Utidjian LH, Karavite D, et al. Rapid Adjustment of Clinical Decision Support in Response to Updated Recommendations for Palivizumab Eligibility. Applied clinical informatics. 2017;8(2):581-92. En.DOI:10.4338/aci-2016-10-ra-0173

32. Forrey AW, McDonald CJ, DeMoor G, et al. Logical observation identifier names and codes (LOINC) database: a public use set of codes and names for electronic reporting of clinical laboratory test results. Clinical chemistry. 1996 Jan;42(1):81-90. PubMed PMID: 8565239. Epub 1996/01/01. eng 
33. National Library of Medicine. RxNorm. Bethesda, MD: National Library of Medicine.948

34. National Center for Health Statistics (NCHS) uabtWHO. International Classification of Diseases, 10th Edition, Clinical Modification. Hyattsville (MD)2017.950

35. Boehm B. A spiral model of software development and enhancement. SIGSOFT Softw Eng Notes. 1986;11(4):1424.DOI:10.1145/12944.12948

36. Misra S, Kumar V, Kumar U, et al. Agile software development practices: evolution, principles, and criticisms. International Journal of Quality \& Reliability Management. 2012;29(9):972-80.

37. Meso P, Jain R. Agile software development: adaptive systems principles and best practices. Information systems management. 2006;23(3):19-30.

38. Kinsman L, Rotter T, James E, et al. What is a clinical pathway? Development of a definition to inform the debate. BMC medicine. 2010 May 27;8:31. PubMed PMID: 20507550. PMCID: 2893088. Epub 2010/05/29. eng.DOI:10.1186/1741-7015-8-31

39. Agency for Healthcare Research and Quality (AHRQ). Learning Health System: U.S. Department of Health \& Human Services; 2017. Available from: https://www.ahrq.gov/learninghealth-systems/about.html

40. Kawamoto K, Del Fiol G, Orton C, et al. System-agnostic clinical decision support services: benefits and challenges for scalable decision support. The open medical informatics journal. 2010;4:245-54. PubMed PMID: 21603281. PMCID: 3097478. Epub 2010/01/01. eng.DOI:10.2174/1874431101004010245

41. HL7. Quality Reporting Document Architecture Implementation Guide for CDA R2. Ann Arbor, MI: Health Level Seven, Inc.; 2012.259

42. Scott P, Worden R. Semantic mapping to simplify deployment of HL7 v3 Clinical Document Architecture. Journal of biomedical informatics. 2012;45(4):697-702.
43. Epic Systems Corporation. EPIC App Orchard Verona, WI: EPIC Systems Corporation; 2017. Available from: https://apporchard.epic.com/

44. Dixon BE, Simonaitis L, Perkins SM, et al. Measuring agreement between decision support reminders: the cloud vs. the local expert. BMC medical informatics and decision making. 2014 Apr 10;14:31. PubMed PMID: 24720863. PMCID: 4004460. Epub 2014/04/12. eng.DOI:10.1186/1472-6947-14-31

45. Dixon BE, Simonaitis L, Goldberg HS, et al. A pilot study of distributed knowledge management and clinical decision support in the cloud. Artificial intelligence in medicine. 2013 Sep;59(1):45-53. PubMed PMID: 23545327. Epub 2013/04/03.

eng.DOI:10.1016/j.artmed.2013.03.004

46. ISO/IEC/IEEE International Standard - Software and systems engineering --Software testing -Part 2:Test processes. ISO/IEC/IEEE 291192:2013(E). 2013:168.DOI:10.1109/ieeestd.2013.6588543

47. Mitchell M, Leas B, Lavenberg J, et al. P247 A Simple guideline appraisal instrument based on IOM standards. BMJ quality \& safety. 2013;22(Suppl 1):A75-A.

48. Shea BJ, Reeves BC, Wells G, et al. AMSTAR 2: a critical appraisal tool for systematic reviews that include randomised or non-randomised studies of healthcare interventions, or both. Bmj. 2017;358:j4008.

49. Jue J, Cunningham S, Lohr K, et al. Developing and Testing the Agency for Healthcare Research and Quality's National Guideline Clearinghouse Extent of Adherence to Trustworthy Standards (NEATS) InstrumentDeveloping and Testing NEATS. Annals of Internal Medicine. 2019;170(7):480-7.DOI:10.7326/m18-2950

50. Ransohoff DF, Pignone M, Sox HC. How to decide whether a clinical practice guideline is trustworthy. JAMA. 2013 Jan 9;309(2):139-40. PubMed PMID: 23299601. Epub 2013/01/10. eng.DOI:10.1001/jama.2012.156703 


\section{Appendix A. eGLIA Report (Limited to Fields With Comments)}

\begin{tabular}{|c|c|c|}
\hline Project: C. Diff Penn Pathway & Final & Comments \\
\hline \multicolumn{3}{|l|}{ Date: 31 Jan 2019} \\
\hline \multicolumn{3}{|l|}{ Recommendations } \\
\hline \multicolumn{3}{|l|}{$\begin{array}{l}\text { D1: Pathway Inclusion: Begin C. diff pathway if } \\
\text { inpatient, positive C. diff test AND clinical } \\
\text { signs/symptoms consistent with CDI }\end{array}$} \\
\hline \multicolumn{3}{|l|}{ Executability } \\
\hline $\begin{array}{l}\text { 12) Would the guideline's intended audience } \\
\text { consistently determine whether each condition in the } \\
\text { recommendation has been satisfied? That is, is each } \\
\text { and every condition described clearly enough so that } \\
\text { reasonable practitioners would agree when the } \\
\text { recommendation should be applied? }\end{array}$ & no & $\begin{array}{l}\text { Three conditions: clinical signs/symptoms need } \\
\text { clarification. } \\
\text { Which C. diff test (any?) Helpful to clarify if } \\
\text { positive C diff test is only serology; also helpful } \\
\text { to list main clinical signs/symptoms; might want } \\
\text { to define clinical signs and symptoms of CDI } \\
\text { Clinical signs/symptoms could be interpreted } \\
\text { differently by different providers. Could also } \\
\text { interpret positive test differently, given some } \\
\text { patients are positive by EIA, and some by PCR. } \\
\text { Some might hesitate to start as other causes are } \\
\text { ruled out, especially if the patient has stabilized } \\
\text { before beginning treatment Would be helpful to } \\
\text { give guidance on clinical signs/symptoms; or } \\
\text { when this does not apply. What are clinical } \\
\text { signs/symptoms? }\end{array}$ \\
\hline $\begin{array}{l}\text { 13) Are all reasonable combinations of conditions } \\
\text { addressed? }\end{array}$ & NA & $\begin{array}{l}\text { Handling of positive tests and negative } \\
\text { symptoms needs to be done. There is a separate } \\
\text { pathway for diagnosing } \mathrm{C} \text {. diff. }\end{array}$ \\
\hline $\begin{array}{l}\text { 18) Does the recommendation specify patient } \\
\text { characteristics (such as coincident drug therapy and } \\
\text { common co-morbid conditions) that require or permit } \\
\text { individualization? }\end{array}$ & yes & $\begin{array}{l}\text { More specification is needed, for instance, do } \\
\text { not treat colonized patients. }\end{array}$ \\
\hline $\begin{array}{l}\text { 19) Does the recommendation specify practice } \\
\text { characteristics (such as location and availability of } \\
\text { support services) that require or permit modification? }\end{array}$ & yes & $\begin{array}{l}\text { Do ICU and Inpatient treat differently inpatient } \\
\text { vs outpatient vs emergency room setting; } \\
\text { "Inpatient" is not defined. What about bedded } \\
\text { outpatients (observation) patients, emergency } \\
\text { room patients (technically outpatients, some } \\
\text { facing long periods of boarding waiting for } \\
\text { rooms). I think the emergency room desperately } \\
\text { needs to use a guideline-based therapy but as } \\
\text { worded they would not be included, and inpatient } \\
\text { therapy tends to follow what the emergency } \\
\text { room starts. }\end{array}$ \\
\hline $\begin{array}{l}\text { 27) Are all patient data needed for this } \\
\text { recommendation available electronically in the } \\
\text { system in which it is to be implemented? }\end{array}$ & no & $\begin{array}{l}\text { Clinical signs/symptoms will need to be } \\
\text { rephrased to make completely computable; } \\
\text { Unclear if clinical signs and symptoms are } \\
\text { available in structured format; might want to } \\
\text { define clinical signs and symptoms of CDI. In } \\
\text { particular positive C. diff assays from our } \\
\text { referring institutions will be missed, as will } \\
\text { preceding days of CDI therapy outside our } \\
\text { system. Patients on extended vancomycin for } \\
\text { CDI diagnosed outside of MUSC will need this } \\
\text { continued at inpatient hospitalization, and their } \\
\text { diarrhea may be long-resolved yet with a } \\
\text { legitimate reason for continued therapy. }\end{array}$ \\
\hline
\end{tabular}




\begin{tabular}{|c|c|c|}
\hline Project: C. Diff Penn Pathway & Final & Comments \\
\hline \multicolumn{3}{|l|}{ Date: 31 Jan 2019} \\
\hline \multicolumn{3}{|l|}{ Recommendations } \\
\hline $\begin{array}{l}\text { 28) Is each condition of the recommendation defined } \\
\text { at a level of specificity suitable for electronic } \\
\text { implementation? }\end{array}$ & no & $\begin{array}{l}\text { Might want to define clinical signs and symptoms } \\
\text { of CDI. Signs and symptoms need to be much } \\
\text { more explicit. Providers should be prompted to } \\
\text { consider toxic megacolon, acute abdomen, and } \\
\text { abrupt cessation of prior diarrhea as potential } \\
\text { presentations of fulminant CDI. }\end{array}$ \\
\hline \multicolumn{3}{|l|}{$\begin{array}{l}\text { O1: Stop Antibiotics: When starting the C. diff } \\
\text { pathway if possible STOP precipitating } \\
\text { antibiotic(s). Discontinue therapy with inciting } \\
\text { antibiotic agent(s) as soon as possible, as this } \\
\text { may influence the risk of CDI recurrence. }\end{array}$} \\
\hline $\begin{array}{l}\text { 10) Is the recommended action (what to do) stated } \\
\text { specifically and unambiguously? That is, would the } \\
\text { intended audience execute the action in a consistent } \\
\text { way? }\end{array}$ & no & $\begin{array}{l}\text { What is ^ASAP"? Inciting antibiotics' -- Would } \\
\text { there be particular antibiotics someone would be } \\
\text { on that you would definitely not blame? If a } \\
\text { patient is on multiple non-C. diff antibiotics, it } \\
\text { may be confusing to know what is the highest } \\
\text { risk or precipitating antibiotic is. }\end{array}$ \\
\hline $\begin{array}{l}\text { 12) Would the guideline's intended audience } \\
\text { consistently determine whether each condition in the } \\
\text { recommendation has been satisfied? That is, is each } \\
\text { and every condition described clearly enough so that } \\
\text { reasonable practitioners would agree when the } \\
\text { recommendation should be applied? }\end{array}$ & no & $\begin{array}{l}\text { Could be helpful to clarify "if possible". Different } \\
\text { providers might interpret "if possible" in different } \\
\text { ways. Also might interpret "precipitating" } \\
\text { antibiotic differently. Could identify a list of } \\
\text { antibiotics to trigger the thought. }\end{array}$ \\
\hline $\begin{array}{l}\text { 18) Does the recommendation specify patient } \\
\text { characteristics (such as coincident drug therapy and } \\
\text { common co-morbid conditions) that require or permit } \\
\text { individualization? }\end{array}$ & yes & $\begin{array}{l}\text { The "if possible" suggests that for some patients } \\
\text { it will not be possible. Identify settings where it } \\
\text { may not be possible to stop. }\end{array}$ \\
\hline $\begin{array}{l}\text { 19) Does the recommendation specify practice } \\
\text { characteristics (such as location and availability of } \\
\text { support services) that require or permit modification? }\end{array}$ & yes & $\begin{array}{l}\text { Infectious disease consult may be indicated } \\
\text { where uncertainty about antibiotic prescribing } \\
\text { exists. }\end{array}$ \\
\hline $\begin{array}{l}\text { 22) Can adherence to this recommendation be } \\
\text { measured? Measurement of adherence requires } \\
\text { attention to both the actions performed and the } \\
\text { circumstances under which the actions are } \\
\text { performed. }\end{array}$ & no & $\begin{array}{l}\text { See comment for ASAP. Would be challenging } \\
\text { to measure how often non-C. diff antibiotics } \\
\text { should be stopped compared to how often they } \\
\text { are stopped, given subjectivity in assessment of } \\
\text { how necessary they are. But would be able to } \\
\text { review orders in C. diff patients to see if } \\
\text { antibiotics were discontinued. Adherence } \\
\text { threshold would be }<100 \% \text {. }\end{array}$ \\
\hline $\begin{array}{l}\text { 28) Is each condition of the recommendation defined } \\
\text { at a level of specificity suitable for electronic } \\
\text { implementation? }\end{array}$ & no & $\begin{array}{l}\text { See above concerns about "if possible" Also, "as } \\
\text { soon as possible" not clear. The condition "if } \\
\text { possible" is a more subjective condition, but the } \\
\text { electronic health record could be utilized to } \\
\text { present current antibiotic orders if possible } \\
\text { definition. The "if possible" is a universe of } \\
\text { issues best sorted out on a case-by-case basis. }\end{array}$ \\
\hline \multicolumn{3}{|l|}{$\begin{array}{l}\text { O2: Stop laxatives: When starting the C. diff } \\
\text { pathway if possible STOP laxatives }\end{array}$} \\
\hline $\begin{array}{l}\text { 10) Is the recommended action (what to do) stated } \\
\text { specifically and unambiguously? That is, would the } \\
\text { intended audience execute the action in a consistent } \\
\text { way? }\end{array}$ & no & $\begin{array}{l}\text { What denotes possible? "If possible" unclear: } \\
\text { what would make it impossible? criteria? }\end{array}$ \\
\hline $\begin{array}{l}\text { 12) Would the guideline's intended audience } \\
\text { consistently determine whether each condition in the } \\
\text { recommendation has been satisfied? That is, is each } \\
\text { and every condition described clearly enough so that } \\
\text { reasonable practitioners would agree when the } \\
\text { recommendation should be applied? }\end{array}$ & yes & $\begin{array}{l}\text { Remove "if possible." Add statement on not for } \\
\text { bowel regimen. }\end{array}$ \\
\hline
\end{tabular}




\begin{tabular}{|l|l|l|}
\hline \multicolumn{1}{|c|}{ Project: C. Diff Penn Pathway } & Final & \multicolumn{1}{c|}{ Comments } \\
\hline Date: 31 Jan 2019 & & \\
\hline Recommendations & & Criteria as previous for when possible and not. \\
\hline $\begin{array}{l}\text { 18) Does the recommendation specify patient } \\
\text { characteristics (such as coincident drug therapy and } \\
\text { common co-morbid conditions) that require or permit } \\
\text { individualization? }\end{array}$ & yes & \\
\hline $\begin{array}{l}\text { 21) Can the recommendation be pilot tested without } \\
\text { substantial resource commitment? For example, } \\
\text { buying and installing expensive equipment to comply } \\
\text { with a recommendation is not easily reversible. }\end{array}$ & yes & $\begin{array}{l}\text { Would just need a marker for not possible. } \\
\text { Best Practice alert would work well. }\end{array}$ \\
\hline $\begin{array}{l}\text { 28) Is each condition of the recommendation defined } \\
\text { at a level of specificity suitable for electronic } \\
\text { implementation? }\end{array}$ & no & Again, unsure about "if possible" \\
\hline
\end{tabular}




\section{Appendix B. Original CDI Pathway}

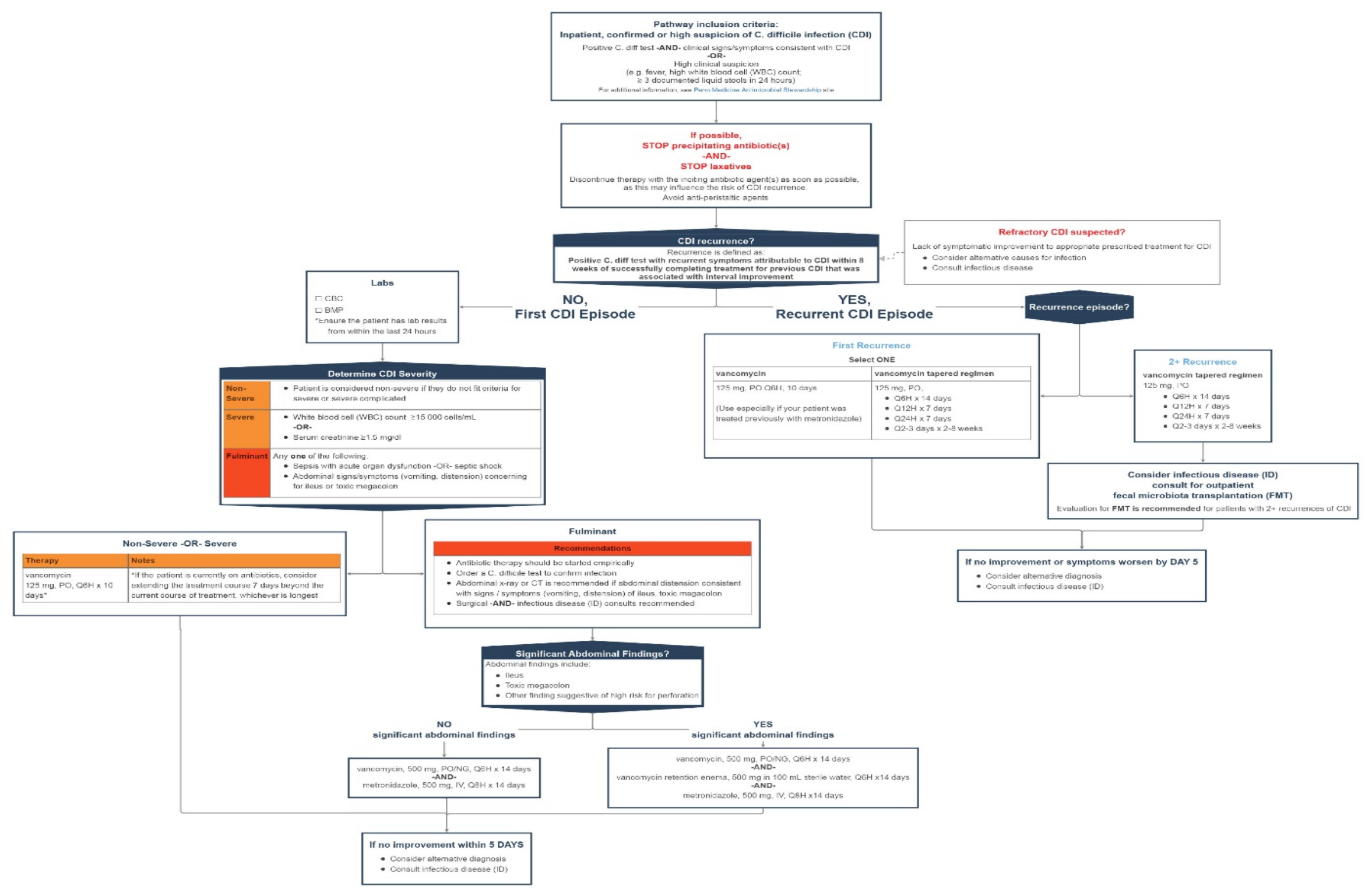




\section{Appendix C. Updated CDI Pathway}

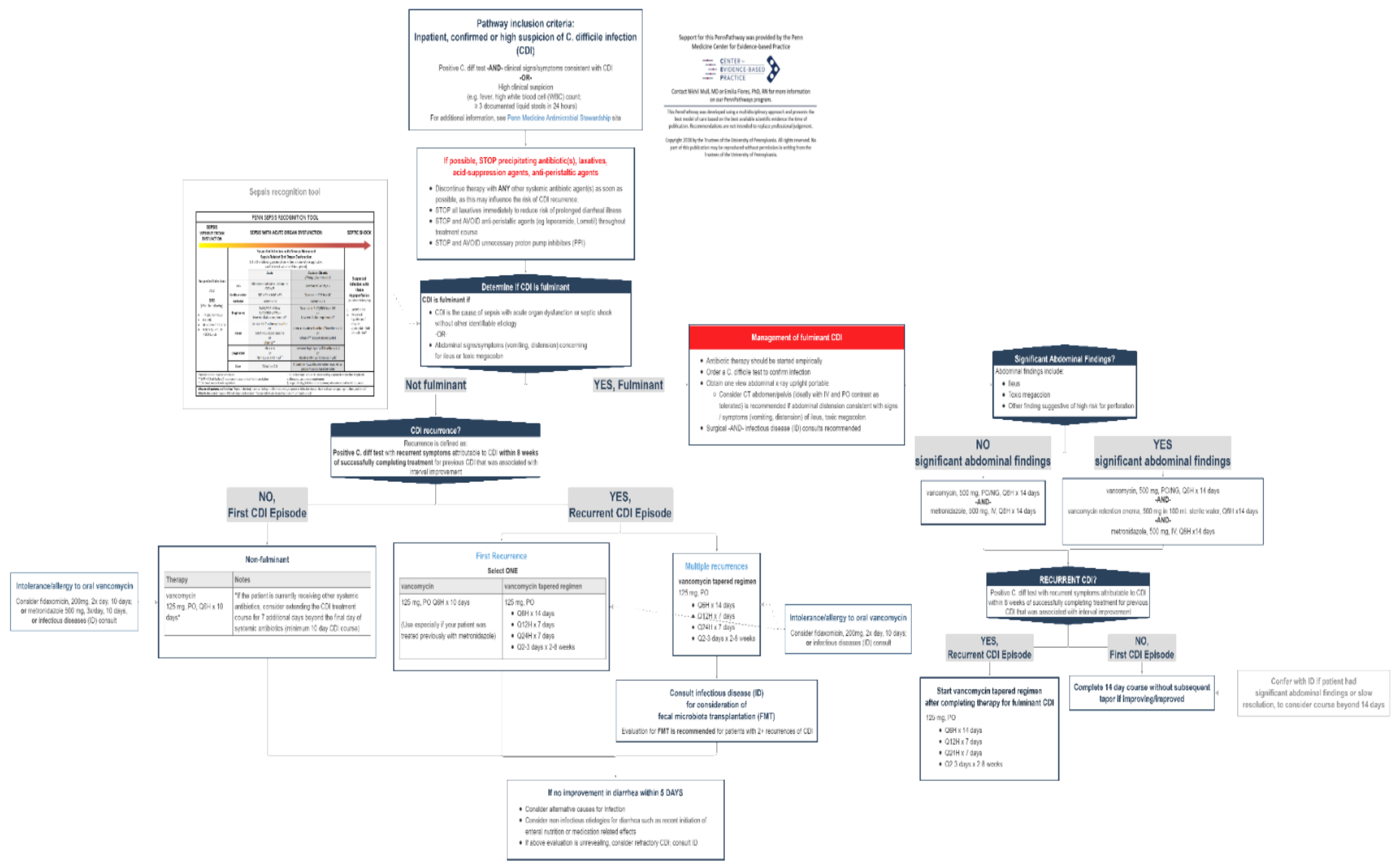




\section{Appendix D. Wireframe Mockup of Penn CDS Artifact}

See the PennPathways: C. difficile Treatment for the UPHS treatment algorithm

STOP Orders

- STOP ANY other systemic antibiotic agent(s) as soon as possible, as this may influence the risk of CDI recurrence.

- $\quad$ STOP all laxatives immediately to reduce risk of prolonged diarrheal illness

- $\quad$ STOP and AVOID anti-peristaltic agents (eg loperamide, Lomotil) throughout treatment course

- $\quad$ STOP and AVOID unnecessary proton pump inhibitors (PPI)

<Print group: administered laxatives, anti-peristaltic agents, PPIs, systemic ABX>

- Uncomplicated/Non-Fulminant infection - Initial/First episode

$\checkmark \square$ Oral Vancomycin (preferred treatment)

Clicking

on the

check box

will allow

the user to

select all

orders

within the

panel with

a single

click. $\square$ Vancomycin PO 125 mg Q6H x 10 days (Preferred Treatment)

$\square$ Add C. Diff to the Problem List

$\square$ Nursing order Document stool volume, frequency, and consistency (Bristol Stool Scale)

$\square$ Nursing order Isolation precautions

- $\square$ Oral Vancomycin ALLERGY/INTOLERANCE?

$\checkmark$ Vancomycin ALLERGY/INTOLERANCE?

O Metronidazole PO $500 \mathrm{mg}$, 3x/day, 10 days, OR

O Fidaxomicin PO 200mg, 2x day, 10 days, OR

Add C. Diff to the Problem List

$\square$ Nursing order Document stool volume, frequency, and consistency (Bristol Stool Scale)

$\square$ Nursing order Isolation precautions (not HUP, Princeton)

$\square$ Infectious Disease Consult (required for fidaxomicin orders)

Uncomplicated/Non-Fulminant infection - FIRST recurrence (symptoms within 8 weeks of previous successful treatment)

- Vancomycin (preferred treatment)

$\checkmark$ Previously treated with metronidazole?

Vancomycin PO $125 \mathrm{mg}$ Q6H x 10 days

Add C. Difficile infection to the Problem List

Nursing order Document stool volume, frequency, and consistency (Bristol Stool Scale)

Nursing order Isolation precautions (not HUP, Princeton)

$\checkmark \square$ NOT previously treated with metronidazole or unknown?

Vancomycin taper order panel Conditional orders

Add C. Difficile infection to the Problem List

Document stool volume, frequency, and consistency (Bristol Stool Scale)

Isolation precautions (not HUP, Princeton)

- Oral Vancomycin ALLERGY/INTOLERANCE?

$\square$ Fidaxomicin PO 200mg, 2x day, 10 days - requires ID consult, can order single dose stat

$\square$ Infectious Disease Consult (required for fidaxomicin orders)

$\square$ Add C. Difficile infection to the Problem List

$\square$ Nursing order Document stool volume, frequency, and consistency (Bristol Stool Scale)

D-1 
Uncomplicated/Non-Fulminant infection - 2+ recurrences (symptoms within 8 weeks of previous successful treatment)

$\checkmark \square$ Oral vancomycin (preferred treatment)

$\square$ Vancomycin taper order panel Conditional orders

$\square$ ID Consult (strong recommendation to evaluate for FMT)

$\square$ Add C. Difficile infection to the Problem List

$\square$ Nursing order Document stool volume, frequency, and consistency (Bristol Stool Scale)

$\square$ Nursing order Isolation precautions (not HUP, Princeton)

- Oral vancomycin ALLERGY/INTOLERANCE?

$\square$ Fidaxomicin PO 200mg, 2x day, 10 days OR

$\square$ ID Consult for FMT consideration (strong recommendation)

$\square$ Add C. Difficile infection to the Problem List

Document stool volume, frequency, and consistency (Bristol Stool Scale)

$\square$ Isolation precautions (not HUP, Princeton)

- Fulminant infection - includes treatments based on episode and severity

- CDI is fulminant if CDI is the cause of sepsis with acute organ dysfunction or septic shock without other identifiable etiology -OR- patient has significant abdominal signs/symptoms (vomiting, distension) concerning for ileus or toxic megacolon

- See the PennPathways: C. difficile Treatment for the UPHS treatment algorithm

$\checkmark$ NO significant abdominal findings (i.e. NO Ileus, toxic megaolon, or findings suggestive of perforation risk)

$\square$ Vancomycin, $500 \mathrm{mg}$, PO/NG, Q6H x 14 days

AND

Metronidazole, $500 \mathrm{mg}$, IV, Q8H x 14 days

Add C. Difficile infection to the Problem List

nursing order Document stool volume, frequency, and consistency (Bristol Stool Scale)

nursing order Isolation precautions (not HUP, Princeton)

$\checkmark \square$ Significant abdominal findings (i.e. patient has Ileus, toxic megaolon, or other findings suggestive of perforation risk)

$\square$ Vancomycin, PO/NG, $500 \mathrm{mg}$, Q6H x 14 days

AND

Vancomycin, enema, $500 \mathrm{mg}$ in $100 \mathrm{~mL}$ sterile water, Q6H x 14 days

AND

$\square$ Metronidazole, IV, $500 \mathrm{mg}$, IV, Q8H x 14 days

Add C. Difficile infection to the Problem List

$\square$ nursing order Document stool volume, frequency, and consistency (Bristol Stool Scale)

$\square$ nursing order Isolation precautions (not HUP, Princeton)

$\checkmark \square$ Select additional treatments if this is a recurrent episode

Recurrent: symptoms within 8 weeks of previous successful treatment)

$\square$ Vancomycin taper order panel - condition order, to start after completing first three 
- Pittsburgh Protocol planned (fulminant infection only in patients undergoing diverting loop ileostomy procedure)

- Diverting loop ileostomy procedure with placement of rectal tube completed by colorectal surgery

- Ordering provider should discontinue all other antimicrobial treatments for $C$. difficile infection

- See the PemnPathways: C. difficile Treatment for the UPHS treatment algorithm

- The following are the post-operative treatments and instructions following PACU care

Antegrade vancomycin flushes (500 mg/500mL LR, Q 8 hours, 10 days, via catheter in ileostomy $\underline{A N D}$

$\square$ Metronidazole IV 500 mg, Q 8 hours, 10 days

$\checkmark \square$ Pittsburgh Protocol Nursing Instructions

$\square$ Clamp red rubber tube catheter for 30 minutes

Document output of rectal manager in flowsheet

Alert surgical team covering provider if major reflux of flush out of the ostomy OR if no rectal output for two hours of more

$\square$ Isolation precautions (not HUP, Princeton)

- Additional treatments if infection is recurrent (Place order AFTER reversal of the diverting loop ileostomy)

- Recurrence: symptoms within 8 weeks of successful treatment of previous episode that was associated with interval improvement

Vancomycin taper order panel - conditional order, to start after fulminant therapy 


\section{Appendix E. Guideline Elements Model (GEM) Report Clostridium difficile (C. Diff) Infection Treatment Pathway}

\section{IDENTITY}

\section{Citation}

- Flores et al, Clostridium difficile (C. Diff) Infection Treatment Pathway, Penn Medicine Center for Evidence-based Practice (CEP) 04 2018, Available at:

https://cds.ahrq.gov/cdsconnect/artifact/clostridium-difficile-c-diff-infection-cdi-treatment-pathway

Date Released

-2018-10-31

GEM Cut History

GEM Cut Version: 1

GEM Cut Author: Jeremy Michel

GEM Cut Date 02/19/2019

\section{DEVELOPER}

Developer Name

- Penn Medicine Center for Evidence-based Practice (CEP)

Conflict Of Interest Policy

Conflict Of Interest Disclosure

\section{PURPOSE}

Objective

\section{INTENDED AUDIENCE}

Intended Users

- Intended for use by providers delivering care in an inpatient setting

Care Setting

- inpatient setting

\section{METHOD OF DEVELOPMENT}

\section{Rating Scheme}

Evidence Quality Rating Scheme

Recommendation Strength Rating Scheme

Qualifying Statement

Patient And Public Involvement

\section{TARGET POPULATION}

\section{Eligibility}

Adults patients in the acute care setting who have a positive CDI test and signs and symptoms of CDI or high clinical suspicion (e.g. temperature $>101.3 \mathrm{~F}$, high white blood count, $>=$ three documented liquid stools in 24-hours)

Inclusion Criterion

- positive CDI test

- signs and symptoms of CDI 
- high clinical suspicion (e.g. temperature $>101.3 \mathrm{~F}$, high white blood count, $>=$ three documented

liquid stools in 24-hours

- adult patient

- inpatient setting

Exclusion Criterion

$\cdot \mathrm{N} / \mathrm{A}$

\section{KNOIVLEDGE COMPONENTS}

\section{DEFINITIONS}

RECOMMENDATION: D1: Pathway Inclusion

Conditional: Begin C. diff pathway if inpatient, positive C. diff test AND clinical signs/symptoms consistent with CDI \{Rec_1:Cond_1

\}

Notes: $\quad$ Not progressing to CDS development as Project presumes CDI and another pathway is used for diagnosis.

RECOMMENDATION: D2: Pathway Inclusion

Conditional: Begin C. diff pathway if inpatient and high clinical suspicion

(e.g. fever, high white blood cell count, $>=3$ documented

liquid stools in 24 hours) $\{\operatorname{Rec} 223$. Cond_23

Notes: $\quad$ Not progressing to CDS development as Project presumes CDI and another pathway is used for diagnosis.

RECOMMENDATION: O1: Stop Antibiotics

Conditional: When starting the $\mathrm{C}$. diff pathway if possible STOP

precipitating antibiotic(s). Discontinue therapy with inciting

antibiotic agent(s) as soon as possible, as this may influence

the risk of CDI recurrence. $\{$ Rec_22:Cond_22 \}

Decision Variable: CDI

Value: true

Action: stop antibiotics (except those for CDI) IF possible.

Value: antibiotics

Type: prevent

Benefit: this may influence the risk of CDI recurrence

Actor: clinician

Verb: discontinue if possible

Complement: if possible

Deontic: should

Risk/Harm: antibiotics may be needed for another illness

\section{Logic:}


If

CDI is [true]

Then

stop antibiotics (except those for CDI) IF possible.

Notes: Intervention would require BPA and is therefore excluded from

Penn Process. However, will be useful for CQL representation of

topic as other sites may have different limitations.

RECOMMENDATION: O2: Stop Laxatives

Conditional: When starting the $\mathrm{C}$. diff pathway if possible STOP laxatives.

$\{$ Rec 21:Cond 21\}

Decision Variable: CDI

Value: true

Action: if possible STOP laxatives.

Value: laxatives

Type: prevent

Benefit: prevent continued diarrhea

Actor: clinician

Complement: is possible

Deontic: should

Risk/Harm: may be needed for non-diarrheal illness

(hepatic encephalopathy)

Logic:

If

$\mathrm{CDI}$ is [true]

Then

if possible STOP laxatives.

RECOMMENDATION: 03: Avoid anti-peristaltic agents

Conditional: When starting the $\mathrm{C}$. diff pathway avoid anti-peristaltic

agents. \{Rec_20:Cond_20 \}

Decision Variable: $\overline{C D I}$

Value: true

Action: avoid anti-peristaltic agents

Value: anti-peristaltic agents

Type: prevent

Actor: clinician

Deontic: should

Logic:

If

CDI is [true]

Then

avoid anti-peristaltic agents 


\section{Appendix F. Value Set Expansion of Clostridium difficile Infection}

Value set name: Clostridioides difficile infection

Code System: ICD10CM, LOINC, ICD9CM, SNOMEDCT

OID: 2.16.840.1.113762.1.4.1130.20

Type: Grouping

Purpose: Clinical Focus -- List of codes representing C. diff infection

Purpose: Data Element Scope -- This value set is intended to work with the data element type, Condition/Diagnosis/Problem

\begin{tabular}{|c|c|c|c|}
\hline Code & Descriptor & Code System & Version \\
\hline 008.45 & Intestinal infection due to Clostridium difficile & ICD9CM & 2013 \\
\hline 10895-1 & Clostridioides difficile toxin B [Presence] in Stool & LOINC & 2.66 \\
\hline $13957-6$ & $\begin{array}{l}\text { Clostridioides difficile toxin A [Presence] in Stool } \\
\text { by Immunoassay }\end{array}$ & LOINC & 2.66 \\
\hline 186431008 & Clostridioides difficile infection (disorder) & SNOMEDCT & 2019-03 \\
\hline $20761-3$ & $\begin{array}{l}\text { Clostridioides difficile [Presence] in Stool by } \\
\text { Agglutination }\end{array}$ & LOINC & 2.66 \\
\hline $20762-1$ & $\begin{array}{l}\text { Clostridioides difficile [Presence] in Stool by Aerobe } \\
\text { culture }\end{array}$ & LOINC & 2.66 \\
\hline 26694-0 & $\begin{array}{l}\text { Clostridioides difficile IgM Ab [Units/volume] in } \\
\text { Serum }\end{array}$ & LOINC & 2.66 \\
\hline $26697-3$ & $\begin{array}{l}\text { Clostridioides difficile IgA Ab [Units/volume] in } \\
\text { Serum }\end{array}$ & LOINC & 2.66 \\
\hline $26702-1$ & $\begin{array}{l}\text { Clostridioides difficile IgG Ab [Units/volume] in } \\
\text { Serum }\end{array}$ & LOINC & 2.66 \\
\hline 310541005 & Clostridium difficile toxin A detected (finding) & SNOMEDCT & $2019-03$ \\
\hline $31308-0$ & Clostridioides difficile Ab [Units/volume] in Serum & LOINC & 2.66 \\
\hline $33947-3$ & $\begin{array}{l}\text { Clostridioides difficile toxin Ab [Titer] in Serum by } \\
\text { Neutralization test }\end{array}$ & LOINC & 2.66 \\
\hline 34468-9 & $\begin{array}{l}\text { Clostridioides difficile toxin A+B [Presence] in Stool } \\
\text { by Immunoassay }\end{array}$ & LOINC & 2.66 \\
\hline $34712-0$ & Clostridioides difficile [Presence] in Stool & LOINC & 2.66 \\
\hline $34713-8$ & Clostridioides difficile toxin $\mathrm{A}+\mathrm{B}$ [Presence] in Stool & LOINC & 2.66 \\
\hline 404907009 & $\begin{array}{l}\text { Toxic megacolon caused by Clostridium difficile } \\
\text { (disorder) }\end{array}$ & SNOMEDCT & 2019-03 \\
\hline 423590009 & Clostridium difficile colitis (disorder) & SNOMEDCT & 2019-03 \\
\hline $43055-3$ & Clostridioides difficile toxin Ab [Titer] in Serum & LOINC & 2.66 \\
\hline $45681-4$ & $\begin{array}{l}\text { Infection with Clostridioides difficile [Minimum } \\
\text { Data Set] }\end{array}$ & LOINC & 2.66 \\
\hline $46131-9$ & $\begin{array}{l}\text { Clostridioides difficile toxin B [Presence] in Stool by } \\
\text { Cytotoxin tissue culture assay }\end{array}$ & LOINC & 2.66 \\
\hline $54067-4$ & $\begin{array}{l}\text { Clostridioides difficile toxin genes [Presence] in } \\
\text { Stool by NAA with probe detection }\end{array}$ & LOINC & 2.66 \\
\hline $562-9$ & $\begin{array}{l}\text { Clostridioides difficile [Presence] in Stool by } \\
\text { Organism specific culture }\end{array}$ & LOINC & 2.66 \\
\hline $563-7$ & $\begin{array}{l}\text { Clostridioides difficile [Presence] in Unspecified } \\
\text { specimen by Organism specific culture }\end{array}$ & LOINC & 2.66 \\
\hline
\end{tabular}




\begin{tabular}{|c|c|c|c|}
\hline Code & Descriptor & Code System & Version \\
\hline $57901-1$ & $\begin{array}{l}\text { Clostridioides difficile glutamate dehydrogenase } \\
\text { [Presence] in Stool }\end{array}$ & LOINC & 2.66 \\
\hline 5891000119102 & Clostridium difficile diarrhea (disorder) & SNOMEDCT & $2019-03$ \\
\hline $61367-9$ & $\begin{array}{l}\text { Clostridioides difficile DNA [Presence] in } \\
\text { Unspecified specimen by NAA with probe detection }\end{array}$ & LOINC & 2.66 \\
\hline $6359-4$ & $\begin{array}{l}\text { Clostridioides difficile toxin A [Units/volume] in } \\
\text { Stool by Immunoassay }\end{array}$ & LOINC & 2.66 \\
\hline $6360-2$ & $\begin{array}{l}\text { Clostridioides difficile toxin A [Units/volume] in } \\
\text { Unspecified specimen by Immunoassay }\end{array}$ & LOINC & 2.66 \\
\hline $6361-0$ & $\begin{array}{l}\text { Clostridioides difficile toxin A+B [Units/volume] in } \\
\text { Serum by Immunoassay }\end{array}$ & LOINC & 2.66 \\
\hline 6362-8 & $\begin{array}{l}\text { Clostridioides difficile toxin A+B [Presence] in Stool } \\
\text { by Cytotoxin tissue culture assay }\end{array}$ & LOINC & 2.66 \\
\hline $6363-6$ & $\begin{array}{l}\text { Clostridioides difficile toxin A+B [Units/volume] in } \\
\text { Stool by Immunoassay }\end{array}$ & LOINC & 2.66 \\
\hline $6364-4$ & $\begin{array}{l}\text { Clostridioides difficile toxin A+B [Units/volume] in } \\
\text { Unspecified specimen by Immunoassay }\end{array}$ & LOINC & 2.66 \\
\hline $6365-1$ & $\begin{array}{l}\text { Clostridioides difficile toxin B [Units/volume] in } \\
\text { Stool by Immunoassay }\end{array}$ & LOINC & 2.66 \\
\hline $6366-9$ & $\begin{array}{l}\text { Clostridioides difficile toxin B [Units/volume] in } \\
\text { Unspecified specimen by Immunoassay }\end{array}$ & LOINC & 2.66 \\
\hline $74822-8$ & $\begin{array}{l}\text { Clostridioides difficile toxin B tcdB gene [Presence] } \\
\text { in Stool by NAA with probe detection }\end{array}$ & LOINC & 2.66 \\
\hline 79177-2 & $\begin{array}{l}\text { Clostridioides difficile glutamate dehydrogenase and } \\
\text { toxins A+B [Presence] in Stool by Rapid } \\
\text { immunoassay }\end{array}$ & LOINC & 2.66 \\
\hline $80685-1$ & $\begin{array}{l}\text { Clostridioides difficile toxin A+B tcdA+tcdB genes } \\
\text { [Presence] in Stool by NAA with probe detection }\end{array}$ & LOINC & 2.66 \\
\hline $82197-5$ & $\begin{array}{l}\text { Clostridioides difficile toxin } \mathrm{A}+\mathrm{B} \text { tcdA+tcdB genes } \\
\text { [Presence] in Stool by NAA with non-probe } \\
\text { detection }\end{array}$ & LOINC & 2.66 \\
\hline $83087-7$ & $\begin{array}{l}\text { Clostridioides difficile glutamate dehydrogenase } \\
\text { [Presence] in Stool by Immunoassay }\end{array}$ & LOINC & 2.66 \\
\hline $87755-5$ & $\begin{array}{l}\text { Clostridioides difficile BI-NAP1-027 strain DNA } \\
\text { [Presence] in Stool by NAA with probe detection }\end{array}$ & LOINC & 2.66 \\
\hline $9365-8$ & Clostridioides difficile $\mathrm{Ab}$ [Titer] in Serum & LOINC & 2.66 \\
\hline A04.7 & Enterocolitis due to Clostridium difficile & ICD10CM & 2020 \\
\hline A04.71 & Enterocolitis due to Clostridium difficile, recurrent & ICD10CM & 2020 \\
\hline A04.72 & $\begin{array}{l}\text { Enterocolitis due to Clostridium difficile, not } \\
\text { specified as recurrent }\end{array}$ & ICD10CM & 2020 \\
\hline
\end{tabular}

F-2 